Review

\title{
Recent Development of Flexible Tactile Sensors and Their Applications
}

\author{
Trong-Danh Nguyen and Jun Seop Lee *(D) \\ Department of Materials Science and Engineering, College of Engineering, Gachon University, \\ Seongnam 13120, Korea; ntdanh041@gachon.ac.kr \\ * Correspondence: junseop@gachon.ac.kr; Tel.: +82-31-750-5814; Fax: +82-31-750-5389
}

Citation: Nguyen, T.-D.; Lee, J.S. Recent Development of Flexible Tactile Sensors and Their Applications. Sensors 2022, 22, 50 . https://doi.org/10.3390/s22010050

Academic Editor: Nunzio Cennamo

Received: 10 November 2021

Accepted: 20 December 2021

Published: 22 December 2021

Publisher's Note: MDPI stays neutral with regard to jurisdictional claims in published maps and institutional affiliations.

Copyright: (C) 2021 by the authors. Licensee MDPI, Basel, Switzerland. This article is an open access article distributed under the terms and conditions of the Creative Commons Attribution (CC BY) license (https:// creativecommons.org/licenses/by/ $4.0 /)$.

\begin{abstract}
With the rapid development of society in recent decades, the wearable sensor has attracted attention for motion-based health care and artificial applications. However, there are still many limitations to applying them in real life, particularly the inconvenience that comes from their large size and non-flexible systems. To solve these problems, flexible small-sized sensors that use body motion as a stimulus are studied to directly collect more accurate and diverse signals. In particular, tactile sensors are applied directly on the skin and provide input signals of motion change for the flexible reading device. This review provides information about different types of tactile sensors and their working mechanisms that are piezoresistive, piezocapacitive, piezoelectric, and triboelectric. Moreover, this review presents not only the applications of the tactile sensor in motion sensing and health care monitoring, but also their contributions in the field of artificial intelligence in recent years. Other applications, such as human behavior studies, are also suggested.
\end{abstract}

Keywords: tactile sensor; flexible; piezoresistive; piezocapacitive; piezoelectric; triboelectric

\section{Introduction}

Tactile sensation, one of the five senses defined by Aristotle, is caused by the excitement of a certain sensitivity in the skin [1,2]. Tactile sensing occurs when biological tissue movements, such as hair movement, or deformation or twisting of the mucous membrane of the skin, occur [3-6]. Specifically, when stimulation with mechanical energy is applied, the shape of the rear container located in the cell membrane changes, opening the ion passage. After that, depolarization occurs as the voltages inside and outside the cell change. This depolarization creates an activity potential, and the generated activity potential is transmitted as an electrical signal to the cerebrum along the axon of the nerve tax mark. With the development of technology, sensors that simulate the tactile transmission process have been developed due to the increase in demand for devices that can sensitively react to external stimuli $[7,8]$. The tactile sensor is a device that detects mechanical external stimuli (e.g., strain, pressure, humidity, sound, and temperature), and transmits an electrical signal $[9,10]$. The signal shows not only the relationship between the stimulus and the device, but also the properties of the stimulus. In detail, it provides data on the magnitude, shape, position, and distribution of forces derived from the tactile sense. Nowadays, scientists tend to develop their tactile sensors into multiarray devices. The structure of these devices usually contains many pixels, with the pixel size becoming smaller and smaller with the new technologies [11,12]. Therefore the sensor became more flexible with higher resolution. On the other side, sensitivity and the range of measurement also attached much attention [13].

To improve the performance of tactile sensors, many researchers have studied sensing materials acting as receptors [14-18]. For example, polarizable materials, such as barium titanate, have not only been made into nanostructures of various shapes, but have also been made into composite materials with other materials to improve the performance of sensing material. In addition, research efforts are being conducted to simplify the existing 
complex signal transmission system by changing the structure of the device, by varying the arrangement of transducers. In addition, tactile sensors that are capable of detecting various external stimuli at the same time by combining devices having different signal transducer systems are also being developed [19]. Depending on the material used to build tactile devices, there are various fabrication techniques. The molding method is the most well-known method, used to construct layers with a complicated structure such as a square block or pyramid $[20,21]$. Besides this, we also have a spinning method that was used to construct fiber structure including electrospinning or wet-spinning [22,23]. We also have some other known methods such as electrodeposition and chemical vapor deposition [24,25].

With the recent further development of technology, tactile sensors are being studied for their application in medical devices and artificial intelligence beyond conventional touch screens or motion sensing applications $[26,27]$. Tactile sensors required in the medical field are used in pulse oscillators, breast cancer screening devices, measurement of pressure distribution in humans, and pressure mats for preventing ascites [28-30]. In the case of artificial intelligence, tactile sensors with high spatial resolution and performance, such as the fingertips of robots, are required [31,32]. For the tactile sensor to be applied to the above application field, data must be obtained directly from the daily activities of the object being tested [33,34]. To this end, the tactile sensor device must overcome multiple sensor element arrangement and wiring processing problems, be implemented flexibly and thinly, and must also be attached to a wide free curved surface. In addition, since physical contact is made, it must be durable and be able to detect various physical quantities $[35,36]$.

This review explains the different operating principles of tactile sensors, and presents the latest development trends to overcome the limitations of each principle-based device. In addition, specific applications in the fields of motion sensors, health care monitoring, and artificial intelligence, which are promising applications of tactile sensor devices, are introduced.

\section{Working Mechanism of the Tactile Sensor}

Tactile detection sensors have been developed to have an operating mechanism that is suitable for the structure and output signal of the device. The four types of operating principles currently used are piezoresistive, piezocapacitive, piezoelectric, and triboelectric. The first case exploits the piezoresistive effect that is strain-induced modulation of the conduction mechanism of a semi-conductor (Figure 1a) [37,38]. Transducers based on this effect usually have low impedance, high sensitivity, and a wide dynamic range. When the device undergoes deformation, the resistance is affected, therefore the output current also changes according to Ohm's law. Transducers based on this effect usually have low impedance, high sensitivity, and a wide dynamic range. The change in $\Delta \mathrm{R}$ in the electrical resistance $R$ of the bar strained in the longitudinal direction is given by:

$$
\Delta \mathrm{R}=\left(1+2 \sigma+\mathrm{M}_{\mathrm{i}}\right) \times \mathrm{R}_{\chi}
$$

where $\sigma$ is Poisson's ratio, $\chi$ is the longitudinal strain, and Mi is dimensionless longitudinal elastoresistance coefficient. The Mi is suggested as following:

$$
\begin{gathered}
\mathrm{M}_{\mathrm{ijkl}}=\pi_{\mathrm{ijkl}} \times \mathrm{Y} \\
\pi_{\mathrm{ijkl}}=\Delta \rho /(\rho \mathrm{T}) \\
\text { and } \mathrm{Y}=\mathrm{T} / \chi
\end{gathered}
$$

where $\mathrm{Y}$ is Young's modulus, $\mathrm{T}$ is stress, and $\rho$ is resistivity. 


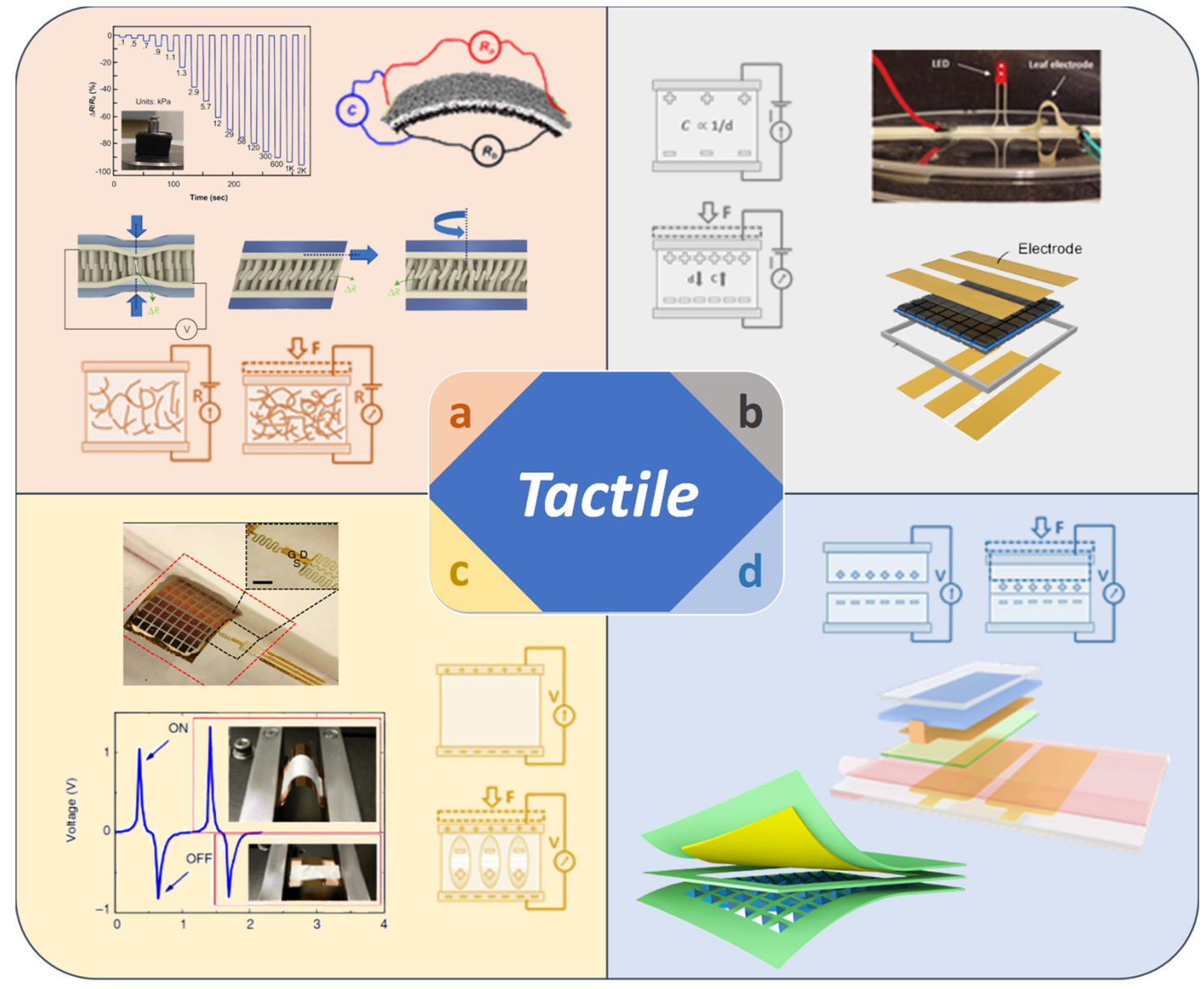

Figure 1. Working mechanism of different tactile sensors: (a) piezoresistive effect; (b) piezocapacitive effect; (c) piezoelectric effect; (d) triboelectric effect.

Secondly, the piezocapacitive effect is based on the working mechanism of a capacitor (Figure 1b) $[39,40]$. Specifically, when the physical structure of the dielectric affected by an external force changes, the output capacitance changes. The equation of working mechanism as following:

$$
\begin{gathered}
\mathrm{C}=\varepsilon \times \mathrm{A} / \mathrm{d} \\
\Delta \mathrm{C} / \mathrm{C}=\Delta \varepsilon / \varepsilon_{0}+\Delta \mathrm{A} / \mathrm{A}-\Delta \mathrm{d} / \mathrm{d}_{0}
\end{gathered}
$$

with $C$ is the sensing capacitance, $A$ is the area of the capacitor, $t$ is the thickness of the dielectric layer, and $\varepsilon$ is the dielectric constant.

Thirdly, the piezoelectric effect is the internal generation reaction of an electric field according to a change in dipole moment resulting from a mechanical strain applied to a crystalline solid (Figure 1c) [41]. The most important factor in this effect is the change in polarization when an external force is applied, which can be caused by the reconstruction of the surrounding dipole, or the change of direction of the molecular moment [42]. Unlike the previous two cases, piezoelectric detection does not require a power supply to operate the device. The working mechanism is expressed as follows:

$$
\begin{aligned}
& S=S_{E} \times T+d \times E \\
& D=d \times t+\varepsilon_{T} \times E
\end{aligned}
$$

where $\mathrm{T}$ is piezoelectric material's stress, $\mathrm{S}$ is strain, $\mathrm{D}$ is charge-density displacement, $\mathrm{E}$ is the electric field, and $d$ is matrix contains the piezoelectric coefficients for material [43]. 
Fourthly, the triboelectric effect is a type of contact electrification that occurs when a particular material is charged, after being separated from the surface of another material (Figure 1d) [44,45]. The basic operating mechanism is described as a charge in which a potential difference periodically occurs on the inner surfaces of two sheets with opposite directional triboelectric charges [46]. Charges are transferred by contact with these surfaces, leaving one as the anode, and the other as the cathode. When separated from the outside, an electric field is generated, and an output voltage is generated by the tactile device [47]. The working mechanism is as follows:

$$
\mathrm{P}_{\mathrm{t}}(\mathrm{t})=\mathrm{V}_{\mathrm{ab}}(\mathrm{t}) \times \mathrm{I}(\mathrm{t})=\mathrm{R} \times \mathrm{I}^{2}(\mathrm{t})+\mathrm{LI}(\mathrm{t}) \times(\mathrm{dI}(\mathrm{t}) / \mathrm{dt})
$$

where $\mathrm{P}$ is power output from the contact-separation mode triboelectric nanogenerator, $\mathrm{R}$ is the system inductance, and I denotes the current flowing the circuit [48].

\subsection{The Piezoresistive Effect-Based Tactile Sensor}

In recent years, piezoresistive devices have been developed based on various materials and device structures to detect changes of stimulus from the outside (Table 1). Previous studies have focused on generating signals according to changes in the energy band of semiconductors [49]. However, in recent years, studies of the application of new composite materials between conductive materials and insulating matrices have also been conducted. Peng et al. reported a device that included three stacks of porous polydimethylsiloxane (PDMS)/silver nanowire (AgNWs), PDMS/PDMS, and carbon nanofibers (CNFs) (Figure 2a) [50]. The sensor showed the ability to have high stretchable and capable of determining three forces simultaneously, namely normal pressure, lateral stretch, and transverse shear force. Due to the elasticity of PDMS and the conductivity via the conductivity of AgNWs and CNFs, it responded well to the changes in resistance while maintaining the strain.

(a)

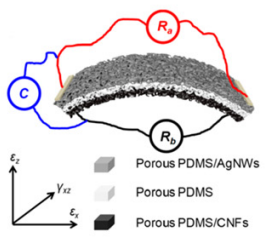

(b)

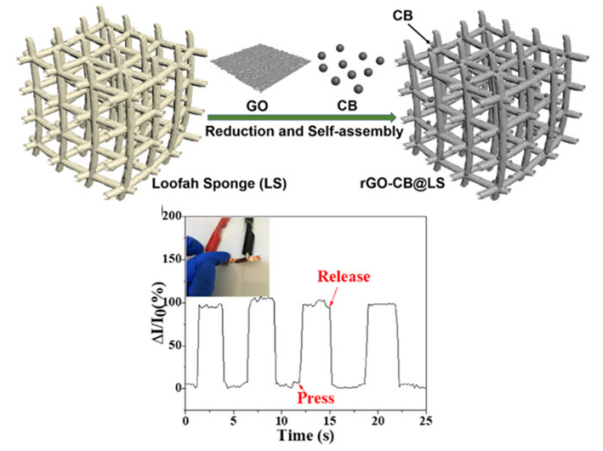

(c)
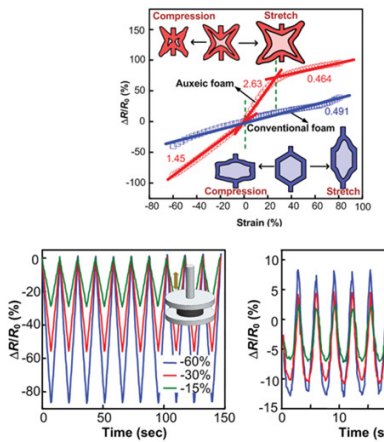

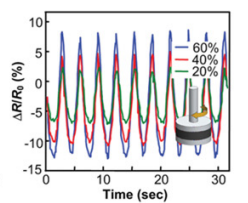

(d)

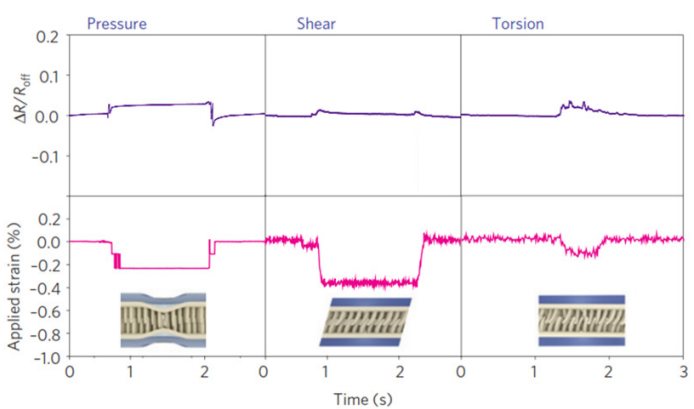

Figure 2. (a) Porous PDMS I PDMS/CNFs I PDMS/AgNWs piezoresistive sensor [50]. (b) Carbon black nanoparticles optimized 3D wearable graphene multifunctional piezoresistive sensor [51]. (c) Piezoresistive based CNT coated auxetic foams [52]. (d) Two interlocked arrays of high-aspectratio Pt-coated polymeric nanofibers supported on thin polydimethylsiloxane layer [53]. 
Table 1. Comparative sensing performances of the piezoresistive-based sensor.

\begin{tabular}{|c|c|c|c|c|c|}
\hline Material & Structure & Application & Sensitivity & Advantage & Ref. \\
\hline Metal alloy & $\begin{array}{l}\text { Circular } \\
\text { ultra-thin film }\end{array}$ & Tactile sensor & $(0.76-4.18) \mathrm{uS} / \mathrm{bar}$ & $\begin{array}{l}\text { High } \\
\text { sensitivity }\end{array}$ & [54] \\
\hline $\mathrm{Cr} / \mathrm{Au}$ & $\begin{array}{l}\text { Thick film } \\
\text { cruciform } \\
\text { Cantilever }\end{array}$ & $\begin{array}{l}\text { Tactile force, shear } \\
\text { stress, fluid flow }\end{array}$ & $0.03 \mathrm{~V} / \mathrm{uN}$ & $\begin{array}{c}\text { Flexible } \\
\text { High sensitivity }\end{array}$ & [55] \\
\hline $\mathrm{NiCr}$ & Thin planar & Tactile sensor & $\begin{array}{c}\text { Curvature: } \\
40 \text { ppm } \\
\text { Force: } \\
340 \mathrm{ppm} / \mathrm{nN} \\
230 \mathrm{ppm} / \mu \mathrm{m}\end{array}$ & Stretchable & [56] \\
\hline $\begin{array}{l}\mathrm{Zr}_{55} \mathrm{Cu}_{30} \mathrm{Ni}_{5} \mathrm{Al}_{10} \\
\text { metallic glass }\end{array}$ & $\begin{array}{c}\text { Flexible } \\
\text { thin-film layer }\end{array}$ & Tactile sensor & $\mathrm{N} / \mathrm{A}$ & $\begin{array}{c}\text { Flexible } \\
\text { High sensitivity }\end{array}$ & [57] \\
\hline Graphene & Cylindrical film & Accelerometer & $2.6 \mathrm{mV} \mathrm{g}^{-1}$ & $\begin{array}{c}\text { Ultralight } \\
\text { High sensitivity }\end{array}$ & [58] \\
\hline $\begin{array}{c}\text { Carbon black } \\
\text { silicone composite }\end{array}$ & Thick film & Pressure sensor & $\mathrm{N} / \mathrm{A}$ & $\begin{array}{l}\text { Stretchability } \\
\text { High sensitivity }\end{array}$ & [59] \\
\hline Polysilicon & Diaphragm & Pressure sensor & (3.35-3.74) $\mathrm{mV} /$ bar & $\begin{array}{l}\text { Single-pixel } \\
\text { mapping sensor }\end{array}$ & [60] \\
\hline Silicone nanowire & Cantilever & Flow sensor & $198 \mathrm{Ohm} \mathrm{ms}^{-1}$ & $\begin{array}{c}\text { High sensitivity } \\
\text { wide measure range }\end{array}$ & [61] \\
\hline rGO foam ${ }^{1}$ & Foam & Pressure sensor & $22.8 \mathrm{kPa}^{-1}$ & $\begin{array}{c}\text { Soft, } \\
\text { high accuracy, } \\
\text { sensitivity }\end{array}$ & [62] \\
\hline $\begin{array}{l}\text { GO-AgNF-PI }{ }^{2} \\
\text { sponge }\end{array}$ & Foam & Pressure sensor & $0.572 \mathrm{kPa}^{-1}$ & $\begin{array}{l}\text { High sensitivity, } \\
\text { accuracy }\end{array}$ & [63] \\
\hline $\mathrm{rGO} / \mathrm{PU}^{3}$ & Thin foam & Pressure sensor & $0.67 \mathrm{kPa}^{-1}$ & $\begin{array}{c}\text { Flexibility, } \\
\text { high sensitivity, } \\
\text { long time stability }\end{array}$ & [64] \\
\hline Polysilicon & Silk surface & $\begin{array}{l}\text { Monitoring human } \\
\text { physiological } \\
\text { signals }\end{array}$ & $1.80 \mathrm{kPa}^{-1}$ & $\begin{array}{l}\text { Wearability, } \\
\text { high sensitivity }\end{array}$ & [65] \\
\hline PEDOT:PSS 4 & Nanofibers & $\begin{array}{l}\text { Bending- } \\
\text { insensitive } \\
\text { pressure sensor } \\
\text { array }\end{array}$ & $\mathrm{N} / \mathrm{A}$ & $\begin{array}{c}\text { Transparency, } \\
\text { flexibility, } \\
\text { wide measure range }\end{array}$ & [66] \\
\hline Carbon & $\begin{array}{c}\text { Planar electrodes, } \\
\text { pyramid }\end{array}$ & Tactile sensor array & $-1.10 \mathrm{kPa}^{-1}$ & $\begin{array}{l}\text { Flexibility, } \\
\text { position mapping, } \\
\text { good accuracy }\end{array}$ & [67] \\
\hline
\end{tabular}

${ }^{1}$ rGO: Reduced graphene oxide. ${ }^{2}$ AgNF: Silver nanofiber. PI: Polyimide. ${ }^{3}$ PU: Polyurethane. ${ }^{4}$ PEDOT:PSS: poly(3,4-ethylene dioxythiophene) polystyrene sulfonate.

With the development of 3D printing technology, it can be used today both with polymers and with composite materials to create very complex structures. Cao et al. used a 3D printer to develop an ultralight 3D hybrid piezoresistive sensor that was inspired by the loofah sponge and reduced graphene oxide (Figure 2b) [51]. Carbon black (CB) was introduced to optimize the conductivity of the reduced graphene oxide while enhancing the sensitivity of the multifunctional hybrid. The device is very small in size, but has high conductivity, short recovery time, excellent stability, and low manufacturing cost. Since traditional foam can provide excellent properties for piezoresistivity, the effect of the tunable Poisson ratio foam material on the piezoresistive effect was also investigated by Li et al. (Figure 2c) [52]. The negative Poisson's ratio of the substrate significantly improves working performance in all three dimensions. Compared to the typical foambased sensor, the auxiliary foam can both be extended laterally by an external force, and offer unique advantages to stretchable sensors and devices. These working conditions make the equipment more comfortable to accommodate the change of shape of a flexible area of the body. 
To enhance the sensitivity of the piezoresistive effect, Pang et al. presented a layered strain-gauge sensor based on nanoscale mechanical interlocking between two arrays of metal-coated, high-aspect ratio nanofiber (Figure 2d) [53]. Mechanical sensing is based on numerous tiny contacts between the neighboring Pt-coated polymer nanofibers, which together created two layers of reversible electric interlocker. The multiplex, flexible straingauge sensor showed excellent response to pressure, shear, and even torsion, with a range smaller than $5 \%$. Moreover, the output signals were proved to be able to maintain stability over 10,000 test cycles.

\subsection{The Piezocapacitive Effect-Based Tactile Sensor}

Due to the simple design, high sensitivity, and fast response characteristics of the capacitor, many studies have been conducted on the piezoelectric tactile sensor [68]. In addition, many methods have recently been proposed to improve wearability while improving the performance of the device (Table 2). Elsayes et al. introduced a plant-based device with the electrode built from leaf skeleton and rose petal as a dielectric layer (Figure 3a) [69]. Silver nanowires (AgNWs) were coated on the outside of the skeletal leaves to form a breathable and flexible interconnected conductive micro-network in the dielectric layer. On the other hand, rose petals that have undergone a freeze-drying process consist of a hierarchical microstructure 3D network, and serve as a compressible architecture that is responsible for sensing [70,71]. In addition, this composite material can be completely decomposed underwater during a short time of 75 days after use, so it can be applied as a disposable device. One of the other ways to increase the flexibility of the piezocapacitive sensor is to increase the number of pixels. Bae et al. introduced a flexible tactile sensor matrix pixelated using mesh layers (Figure 3b) [72]. The sensor matrix is uniformly patterned and electrically isolated between pixels using carbon nanotubes (CNTs) and polydimethylsiloxane (PDMS) composite materials. In addition, with the help of the mesh structure, confusion of the detection signal is prevented, and the detection layer is strengthened. Thus, this tactile sensor shows that the pressure exerted by the device is detected sensitively and independently.

Recently, other groups have attempted to combine piezocapacitive function with other elements, such as field-effect transistors (FETs). Mansfeld et al. proposed an organic thinfilm pressure sensing device in which one of the core layers is a transistor structure, while the dielectric is made of rubber material (Figure 3c) [73]. The needle-like structure and flexibility of PDMS thin films allowed the device to measure human tissues and living cells $[74,75]$.

The fast response time of the piezoelectricity sensor allows rapid collection of pressure information, and shows the possibility of application to artificial intelligence applications. Boutry et al. demonstrated a device that was capable of measuring and distinguishing both shear and pressing forces in real-time using a hierarchical pattern (Figure 3d) [76]. The structure of the sensor was created using the hierarchical structure of the sunflower to optimize the performance of the piezoelectric. Therefore, this sensor system not only detects small changes in the motion of the robot arm, but also suggests the possibility of controlling it for various purposes in the future [77]. 
(a)
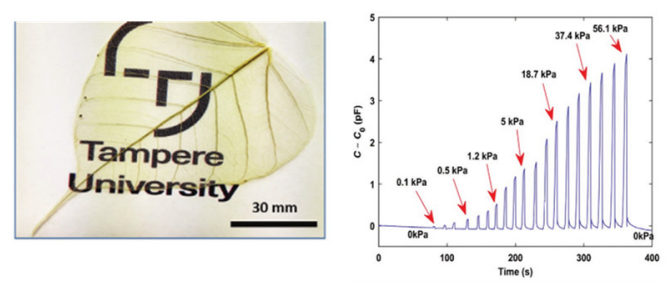

(b)
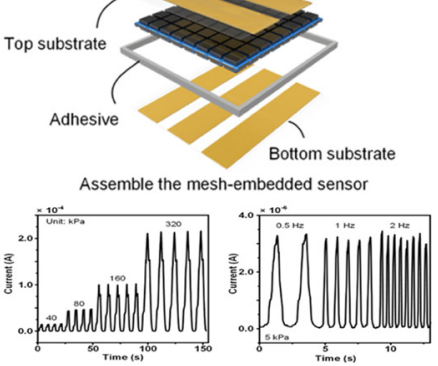

(c)

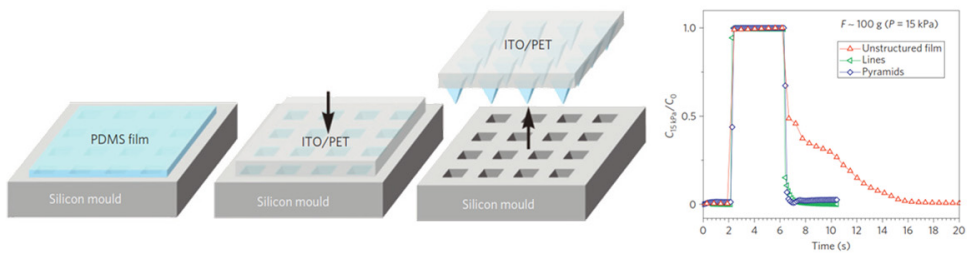

(d)
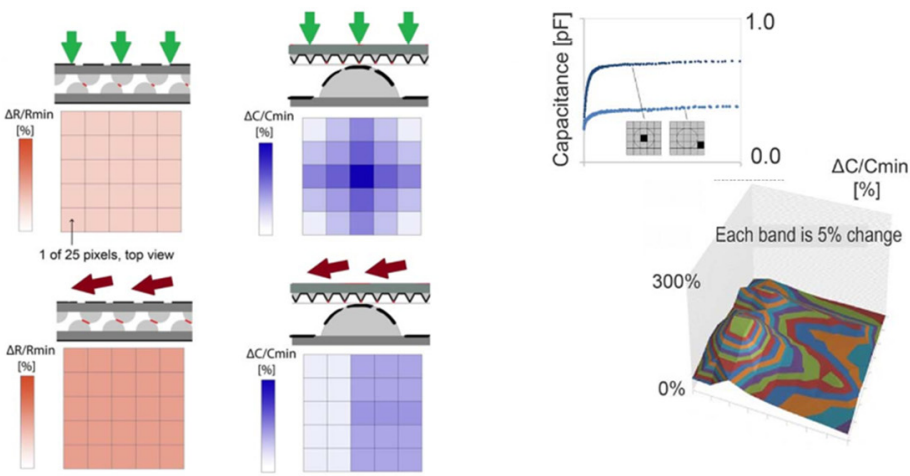

Figure 3. (a) Tactile sensor made from dielectric rose petal layer between two leaf electrodes [69]. (b) A proposed sensor utilizing fiberglass mesh [72]. (c) Pyramid microstructure PDMS films for piezocapacitance [73]. (d) Biomimetic e-skins with interlocked microstructure [76].

Table 2. Comparative sensing performances of the piezocapacitive-based sensor.

\begin{tabular}{|c|c|c|c|c|c|}
\hline Material & Structure & Application & Sensitivity & Advantage & Ref. \\
\hline 3D fabric & Planar fabric & $\begin{array}{l}\text { Tactile system } \\
\text { for robots }\end{array}$ & $\begin{array}{c}(0.86-2.50) \mathrm{fF} \\
\mathrm{kPa}^{-1}\end{array}$ & Very sensitivity & [78] \\
\hline Graphene & Planar & Pressor sensor array & $6.55 \% \mathrm{kPa}^{-1}$ & $\begin{array}{l}\text { Long time stability, } \\
\text { position mapping, } \\
\text { high resolution }\end{array}$ & [79] \\
\hline $\begin{array}{c}\mathrm{AgNF}-\mathrm{AgNW}{ }^{1} \\
\text { and } \mathrm{SiO}_{2}\end{array}$ & Fiber & Pressor sensor array & $\begin{array}{c}1.78 \times 10^{-3} \\
\sim 9.65 \times 10^{-5} \\
\mathrm{kPa}^{-1}\end{array}$ & $\begin{array}{l}\text { Transparent, } \\
\text { position mapping, } \\
\text { high resolution }\end{array}$ & [80] \\
\hline PDMS/Ecoflex ${ }^{2}$ & Planar/shoe sole & $\begin{array}{l}\text { Plantar pressure } \\
\text { sensor in shoes }\end{array}$ & $6.8 \% \mathrm{~N}^{-1}$ & $\begin{array}{c}\text { Wearable, } \\
\text { high sensibility, } \\
\text { wide measure range }\end{array}$ & [81] \\
\hline PDMS/Ecoflex & $\begin{array}{c}\text { Planar/ } \\
\text { pump bottom }\end{array}$ & $\begin{array}{l}\text { Normal and shear } \\
\text { force sensor }\end{array}$ & $(2.5-3.0) \% \mathrm{mN}^{-1}$ & $\begin{array}{l}\text { High sensitivity, } \\
\text { position mapping }\end{array}$ & [82] \\
\hline
\end{tabular}


Table 2. Cont.

\begin{tabular}{|c|c|c|c|c|c|}
\hline Material & Structure & Application & Sensitivity & Advantage & Ref. \\
\hline $\begin{array}{c}\text { Ag NWs / } \\
\text { PDMS/CPI }^{3}\end{array}$ & $\begin{array}{c}\text { Lotus mold } \\
\text { substrate/ } \\
\text { AgNWs electrode }\end{array}$ & $\begin{array}{l}\text { Tactile sensor } \\
\text { for e-skin }\end{array}$ & $1.2 \mathrm{kPa}^{-1}$ & $\begin{array}{c}\text { Flexible, } \\
\text { high sensitivity, } \\
\text { high aspect ratio }\end{array}$ & [83] \\
\hline Ionic liquid ${ }^{4}$ & Planar & 3D force sensor & $29.8 \mathrm{nF} \mathrm{N}^{-1}$ & $\begin{array}{l}\text { Be able to measure } \\
\text { three-dimensional contact } \\
\text { force }\end{array}$ & [84] \\
\hline Ag/Ecoflex & Planar & $\begin{array}{l}\text { Static and dynamic } \\
\text { strain mapping }\end{array}$ & $1.45 \mathrm{MPa}^{-1}$ & $\begin{array}{c}\text { Wearable, } \\
\text { dynamic strain } \\
\text { mapping }\end{array}$ & [85] \\
\hline
\end{tabular}

${ }^{1}$ AgNF-AgNW: Silver nanofiber-silver nanowire. ${ }^{2}$ Ecoflex: Low viscosity, soft, platinum-catalyzed silicone rubber. ${ }^{3} \mathrm{Ag}$ NWs/PDMS/CPI: Silver nanowires/PDMS/Colorless polyimide. ${ }^{4}$ Ionic liquid: 1-ethyl-3methylimidazolium tricyanomethanide.

\subsection{The Piezoelectric Effect-Based Tactile Sensor}

The piezoelectric effect is widely used in sensor, actuator, and transducer applications, due to the operating principle of generating electricity from external stimuli. Many studies have shown that dielectric materials are suitable for application to piezoelectricbased sensor devices (Table 3) $[86,87]$. As one of the dielectric materials, barium titanate $\left(\mathrm{BaTiO}_{3}\right)$ is the most widely used substance, since it has environment-friendly properties, along with excellent dielectric constants and piezoelectric properties [88]. Furthermore, a composite material was produced using poly(vinylidene fluoride) (PVDF) to improve the physical properties of the $\mathrm{BaTiO}_{3}$. Jiang et al. proposed a piezoelectric sensor that was composed of PVDF fibers doped with $\mathrm{BaTiO}_{3}$ nanoparticles $\left(\mathrm{BaTiO}_{3} \mathrm{NPs}\right)$ using electrospinning (Figure 4a) [89]. In the composite fiber structure, $\mathrm{BaTiO}_{3} \mathrm{NPs}$ also acted as nucleation sites for the formation of the $\beta$ phase of PVDF, inducing the generation of high piezoelectricity in the device.

(a)
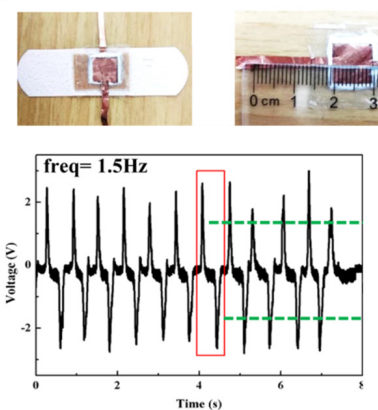

(c)

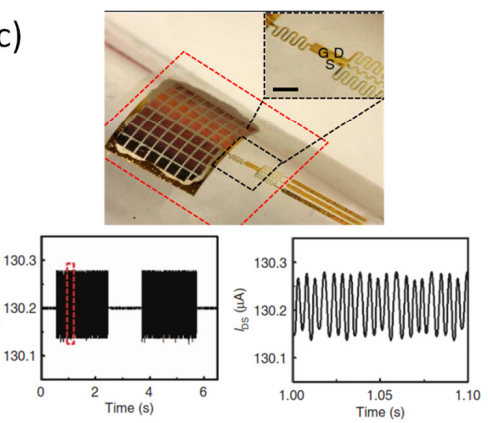

(b)
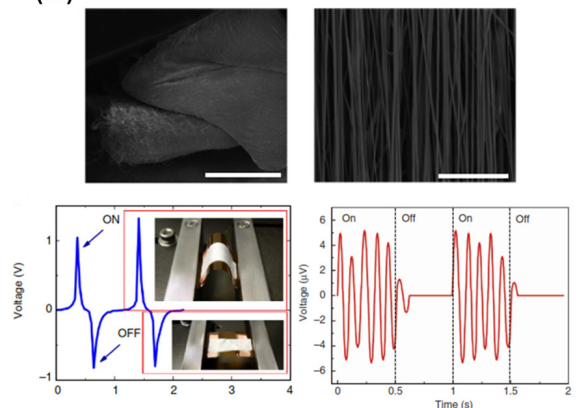

(d)

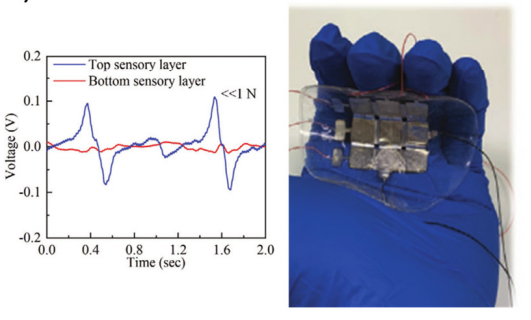

Figure 4. (a) Electrospun $\mathrm{BaTiO}_{3} / \mathrm{Poly}$ (vinylidene fluoride) nanocomposite membrane [89]. (b) Aligned arrays of nanofibers of poly(vinylidenefluoride-co-trifluoroethylene) for piezoelectric [90]. (c) Conformable amplified lead zirconate titanate (PZT) sensor [91]. (d) Crosstalk electrodes for spatiotemporally distinguishing diverse stimuli [92]. 
Table 3. Comparative sensing performances of the piezoelectric-based sensor.

\begin{tabular}{|c|c|c|c|c|c|}
\hline Material & Structure & Application & Sensitivity & Advantage & Ref. \\
\hline $\begin{array}{l}\mathrm{P}(\mathrm{VDF}-\mathrm{TrFE}) / \\
\mathrm{BaTiO}_{3} 1\end{array}$ & $\begin{array}{l}\text { Composite } \\
\text { microfiber }\end{array}$ & $\begin{array}{l}\text { Bending motion sensor for } \\
\text { gesture }\end{array}$ & $0.33 \mathrm{~V} \mathrm{kPa}^{-1}$ & $\begin{array}{l}\text { Flexibility, } \\
\text { high accuracy }\end{array}$ & [93] \\
\hline $\mathrm{BaTiO}_{3}$ & Fiber/fabric & $\begin{array}{l}\text { Wearable physiological } \\
\text { sensing }\end{array}$ & $1.44 \mathrm{~V} \mathrm{~N}^{-1}$ & $\begin{array}{l}\text { Flexibility, } \\
\text { High accuracy }\end{array}$ & [94] \\
\hline $\mathrm{P}(\mathrm{VDF}-\mathrm{TrFE})$ & Planar & $\begin{array}{l}\text { Movement monitoring } \\
\text { and e-skin }\end{array}$ & $\mathrm{N} / \mathrm{A}$ & $\begin{array}{l}\text { Transparency, } \\
\text { high accuracy, } \\
\text { fast response }\end{array}$ & [95] \\
\hline $\mathrm{Pb}\left[\mathrm{Zr}_{\mathrm{x}}, \mathrm{Ti}_{1-\mathrm{x}}\right] \mathrm{O}_{3}$ & Thick block & Pulse monitoring & $0.018 \mathrm{kPa}^{-1}$ & $\begin{array}{l}\text { Ultrathin, } \\
\text { high sensitivity, } \\
\text { long time stability }\end{array}$ & [96] \\
\hline $\mathrm{PbI}_{2}$ & Planar & $\begin{array}{c}\text { Motion sensor/ } \\
\text { Environment vibration }\end{array}$ & $\mathrm{N} / \mathrm{A}$ & $\begin{array}{l}\text { Stretchability, } \\
\text { long time stability, } \\
\text { high sensitivity }\end{array}$ & [97] \\
\hline PVDF $^{2}$ & Nanofiber & Strain sensor & $\mathrm{N} / \mathrm{A}$ & $\begin{array}{c}\text { Stretchability, } \\
\text { Wide measure range }\end{array}$ & [98] \\
\hline PVDF & Thin film planar & Human motion & $\begin{array}{c}1.5 \times 10^{-5} \mathrm{~V} \\
\mathrm{mN}^{-1}\end{array}$ & High sensitivity & [99] \\
\hline $\begin{array}{l}\text { PMMA }^{3} \\
\text { p-GaN }\end{array}$ & $\begin{array}{l}\text { Vertical fiber } \\
\text { Planar }\end{array}$ & Digital imaging & $12.88 \mathrm{GPa}^{-1}$ & $\begin{array}{l}\text { High resolution } \\
\text { Flexibility }\end{array}$ & [100] \\
\hline $\mathrm{MoS}_{2}$ & Single atom layer & Energy conversion & $\mathrm{N} / \mathrm{A}$ & $\begin{array}{l}\text { Flexibility, } \\
\text { Transparence, }\end{array}$ & [101] \\
\hline
\end{tabular}

In addition, studies are being conducted to maximize piezoelectric performance by modifying the structure of polymer materials having dielectric properties. Chen et al. suggested the $\mathrm{P}(\mathrm{VDF}-\mathrm{TrFe})$ (poly(vinylidene fluoride-co-trifluoroethylene)) aligned nanofiberbased tactile sensor using an electrospinning process (Figure $4 \mathrm{~b}$ ) [90]. The aligned polymer membrane-based tactile sensor showed an excellent piezoelectric effect (up to $40 \mathrm{nA}$ and $1.5 \mathrm{~V}$ ) with freestanding, high-density arrays. Moreover, this device presented a rapid response with periodical stimuli from any orientation.

To fully use the high conductivity and output power of the inorganic dielectric material, the development of a device through miniaturization of the inorganic element is in progress. To overcome the inflexible properties of inorganic ingredients, Dagdeviron et al. developed a design and theoretical model for ultra-small devices that can be attached to the skin (Figure 4c) [91]. This device consisted of a small-sized lead zirconate titanate (PZT) thin film on a soft substrate to provide stretchability. The compliant properties of the PZT thin film provide high performance without the interference of sensing signals at the same time as the rapid response of the equipment.

In addition to the development of flexible piezoelectric devices, studies of the arrangement of multi-pixel devices have been conducted. Lin et al. proposed a new piezoelectric flexible multifunctional tactile array that can distinguish various external stimulation modes in real-time using a simple but effective cross-talk free topology (Figure 4d) [92]. The designed tactile array has spatiotemporal detection and distinction ability of the magnitude, position, and diverse behavior, including touching, slipping, and bending.

\subsection{The Triboelectric Effect-Based Tactile Sensor}

The triboelectric effect was initially used as a power supply device, but due to its high efficiency, lightweight, low cost, environmental affinity, and usability at low frequencies, it is also used in tactile sensors (Table 4) [102-105]. To date, many studies have been conducted of the material showing a triboelectric effect and its charge density (Figure 5) [106]. However, not many studies have been conducted to apply the materials to the tactile sensor, due to its sensitive nature to environmental changes (e.g., presence of humidity, water, and dust on the friction surface) [107]. To overcome such problems, Chen et al. developed a 
fully encapsulated and scalable device (Figure 6a) [108]. The sensor device was made in the form of a single electrode consisting of polyurethane nanofibers (PUNFs) and silver nanofibers (AgNFs) covered with a PDMS container. This sensor device exhibits sensitive reactivity to friction acting from various angles, while preventing moisture penetration, due to the effect of the PDML layer.

In addition, sensor devices of various structures have been proposed to increase the elasticity of the electrode. Dong et al. developed a simple and flexible tactile sensor using a continuous chain link fence-shaped conductive silver-plated nylon yarn network (Figure 6b) [109]. The zigzag shape of the yarn plays an important role in improving the elasticity of the device. In addition, the location of the yarn is built between two layers of silicone rubber, therefore it has excellent sensitivity, high detection resolution, and fast response time. In addition, by constructing a pixel device, the fiber-based sensor can simultaneously shape the change in stimulation according to the location in 2D.

Since the two electrode systems of the triboelectric device cause signal interference due to the connection of the device, a device composed of one electrode is being developed to solve this problem. Yang et al. presented a single electrode-based triboelectric device based on periodic overlap and separation between a polytetrafluoroethylene (PTFE) and aluminum layers using relative sliding motion (Figure 6c) [110]. Specifically, a periodic change in the contact region between the polytetrafluoroethylene (PTFE) and an aluminum layer causes electrostatic and triboelectric effects, thereby generating movement of charges between the two layers. In addition, a single electrode-based device can be applied as a wireless sensor, due to its simple structure and operating principle.

Furthermore, research is being conducted to improve the output performance of the device by using operations such as electrode material change, surface modification, ion injection, and environmental control. He et al. expanded the charge movement space of the device by proposing a new structure of the sliding mode to improve the surface density of the electrode (Figure 6d) [111]. The device incorporates a structure between a shielding layer on a slider and an alternating blank-tribo-area to expand charge transfer. In addition, the structure can be expanded to be applied to a rotating device having high charging output density at low frequency.

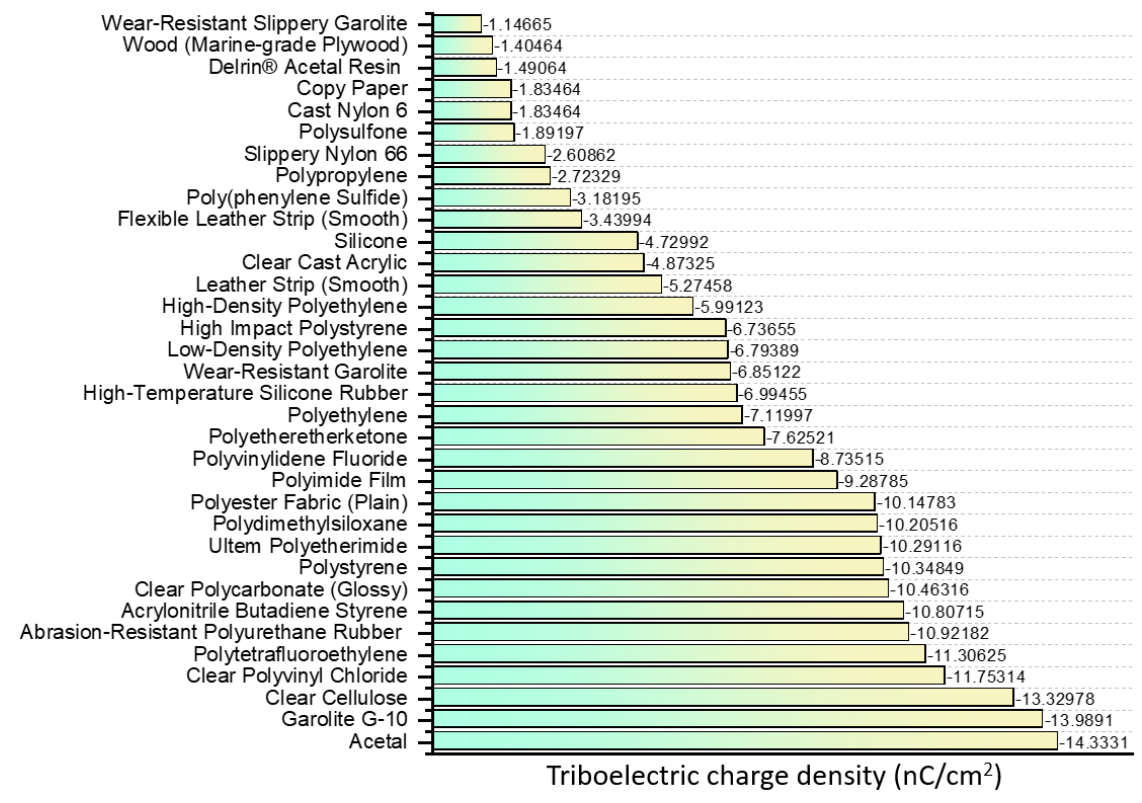

Figure 5. Familiar materials used for triboelectric and their triboelectric charge density [106]. 
(a)

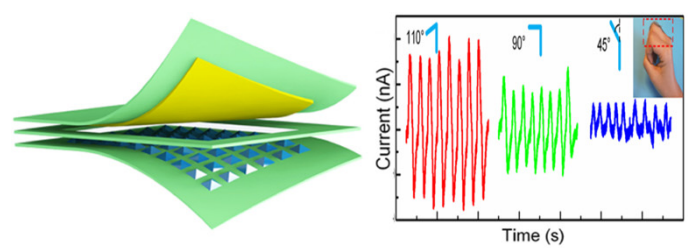

(b)

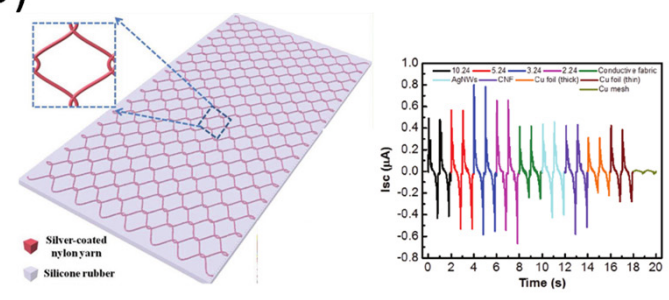

(c)

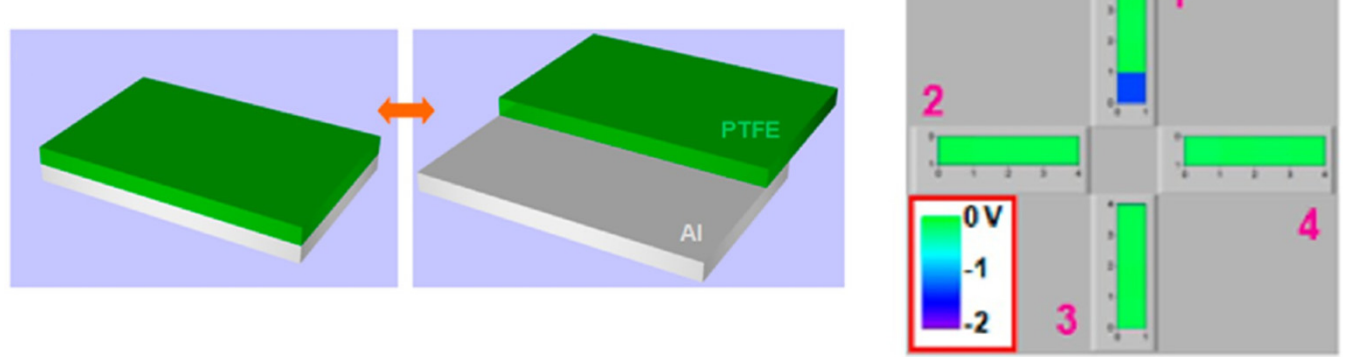

(d)
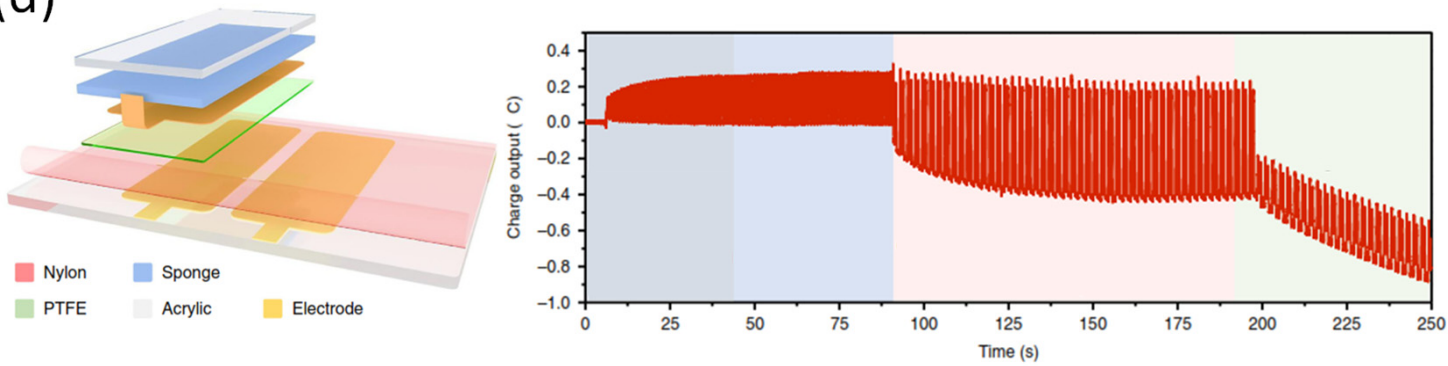

Figure 6. (a) Waterproof and stretchable triboelectric tactile sensor [108]. (b) Silver-coated nylon yarn on silicone rubber for skin-inspired triboelectric [109]. (c) Single-electrode based sliding triboelectric for vector sensor [110]. (d) Sliding mode triboelectric by charge space-accumulation effect [111].

Table 4. Comparative sensing performances of the triboelectric-based sensor.

\begin{tabular}{|c|c|c|c|c|c|}
\hline Material & Structure & Application & Sensitivity & Advantage & Ref. \\
\hline $\mathrm{Hg} / \mathrm{PVDF}$ & $\begin{array}{l}\text { Liquid metal/ } \\
\text { Microfiber }\end{array}$ & Acceleration sensor & 0.26 vs. $\mathrm{m}^{-1}$ & $\begin{array}{l}\text { Very high } \\
\text { accuracy }\end{array}$ & [112] \\
\hline PEDOT:PSS & Planar with wrinkle & Motion senor & $\begin{array}{c}(0.008-0.08) \\
\mathrm{kPa}^{-1}\end{array}$ & $\begin{array}{l}\text { Stretchability, } \\
\text { high accuracy }\end{array}$ & [113] \\
\hline $\begin{array}{c}\text { Silicone } \\
\text { rubber/AgNWs }\end{array}$ & $\begin{array}{c}\text { Nanowires } \\
\text { sandwich by silicone }\end{array}$ & Motion sensor & $0.034 \mathrm{~V} \mathrm{~Pa}^{-1}$ & $\begin{array}{l}\text { Stretchability, } \\
\text { high accuracy, } \\
\text { long time stability }\end{array}$ & [114] \\
\hline $\mathrm{PTFE}^{1} / \mathrm{Cu}$ & Gate for transistor & $\begin{array}{l}\text { Touch tactile } \\
\text { array system }\end{array}$ & $(0.0778-1.028) \mathrm{mm}^{-1}$ & $\begin{array}{l}\text { Flexibility, } \\
\text { Long time stability, } \\
\text { Position mapping }\end{array}$ & [115] \\
\hline PVA $^{2}$ & $\begin{array}{l}\text { Microfiber on } \\
\text { PDMS substrate }\end{array}$ & Touching sensor & 4.4 Pa & $\begin{array}{c}\text { Transparence, } \\
\text { stretchability, } \\
\text { long time stability }\end{array}$ & [116] \\
\hline Graphene & Planar & $\begin{array}{l}\text { TENG }^{3} \text { mimics fast } \\
\text { adapting of } \\
\text { the neuron system }\end{array}$ & $(0.04-1.64) \mathrm{kPa}^{-1}$ & $\begin{array}{l}\text { High resolution, } \\
\text { high sensitivity, } \\
\text { position mapping, } \\
\text { flexibility }\end{array}$ & [117] \\
\hline $\mathrm{ITO}^{4} / \mathrm{PDMS}$ & $\begin{array}{c}\text { Planar/Pyramid } \\
\text { on planar }\end{array}$ & Tactile sensor array & $2.82 \mathrm{~V} \mathrm{~Pa}^{-1}$ & $\begin{array}{c}\text { Flexibility, } \\
\text { wide measurement range, } \\
\text { position mapping } \\
\text { high accuracy }\end{array}$ & [118] \\
\hline
\end{tabular}


Table 4. Cont.

\begin{tabular}{|c|c|c|c|c|c|}
\hline Material & Structure & Application & Sensitivity & Advantage & Ref. \\
\hline $\begin{array}{c}\text { Fluorinated } \\
\text { ethylene } \\
\text { propylene }\end{array}$ & $\begin{array}{l}\text { Planar with } \\
\text { vertical fiber }\end{array}$ & Touching sensor & $\begin{array}{c}44 \mathrm{mV} \\
1.1 \mathrm{~V} / \mathrm{Pa}\end{array}$ & $\begin{array}{l}\text { Ultra-sensitivity, } \\
\text { flexibility, } \\
\text { transparency }\end{array}$ & [119] \\
\hline $\begin{array}{c}\text { PDMS } \\
\text { PAAm }{ }^{5}-\mathrm{LiCl}\end{array}$ & $\begin{array}{c}\text { Elastomers } \\
\text { contain hydrogel }\end{array}$ & $\begin{array}{l}\text { Flexible, transparent } \\
\text { motion sensor }\end{array}$ & $0.013 \mathrm{kPa}^{-1}$ & Ultra-stretchability & {$[120]$} \\
\hline HCOENPs/BP/PET 6 & $\begin{array}{l}\text { PET fabric coat black } \\
\text { phosphorus } \\
\text { and particles }\end{array}$ & $\begin{array}{l}\text { Motion sensor for } \\
\text { artificial intelligence }\end{array}$ & $\mathrm{N} / \mathrm{A}$ & $\begin{array}{c}\text { Wearable, } \\
\text { high accuracy, } \\
\text { long time stability }\end{array}$ & [121] \\
\hline PTFE & PTFE sandwich $\mathrm{Cu}$ & Water/air low sensor & $\mathrm{N} / \mathrm{A}$ & High accuracy & [122] \\
\hline
\end{tabular}

\subsection{Optical Tactile Sensor}

Besides the electrical base tactile device, there is another stimulus detecting device type called an "optical tactile sensor". The optical sensor uses materials that can generate light signals with different wavelengths, reflection, polarization, color, and intensity (Table 5) [123-127]. These devices have many advantages, such as low thermal noises and stray capacitances. However, they suffer from medium power required as well as integration complexity [128].

Gu et al. introduced a stretchable strain optical device based on the change of optical transmittance of the CNTs embedded on Ecoflex film (Figure 7a) [129]. Ecoflex material provides the sensor with outstanding mechanical properties including low Young's modulus, good mechanical durability, and flexibility. Using spray-coating, multiwalled CNTs were applied on the surface of Ecoflex. The stretchability of the device can reach the point of $400 \%$ stretching with high sensitivity, stability, and reproductivity. The sensor was then demonstrated as a practical monitoring device applied to human skin. It is mentioned also that the sensor was able to distinguish the motion of finger-/wrist-bending, neck pulse/posture, swallowing, and face motion. Yi et al. presented an ultra-adaptable and stably wearable photonic skin (Figure 7b) [130]. The sensor can reversibly adhere to diverse substrates and visualize the external stimuli based on harnessing the liquid crystalline phase and amorphous phase of hydroxypropyl cellulose (HPC). The work also included an adhesive layer made from HPC, with the ability to change shape and shape recovery. The adhesive layer has been proven to have the capacity to be reused many times. Furthermore, since the HPC sensing layer reflects the light from the environment, the device does not require any additional power supply. The reflected light will change responding to the applied stress or strain of the HPC layer. However, the said advantage also means that the device cannot function when there is no light from the environment. The optional CNT electronic sensor in the middle of the device had confirmed that the optical sensing pad had high accuracy tower pressing force and strain.

A flexible pressure sensor matrix for recording both the handwritten graphics habits has been introduced by Wang et al. (Figure 7c) [131]. It is widely known that one of the most common methods for identifying verifications is an electronic signature according to the unique pressure/force applied on the sensing panel $[132,133]$. The device was built based on the ZnS:Mn particles as mechanoluminescent material sandwiched by polymeric layers. The applied pressure can provide energy for the particle so that it can emit the light with intensity responding to different strengths of the force, with a range from $0.6 \sim 50 \mathrm{MPa}$. Although the weak signal must be collected by a reading system, the response time is less than $10 \mathrm{~ms}$ with high spatial resolution. Jeong et al. demonstrated a mechanoluminescent (ML) fabric that can emit light using energy only from human motion (Figure 7d) [134]. In this case, the ML threads were woven into the textile, thus creating a wearable device that reduces energy waste. The binding of PDMS/ZnS with the fabricated cross shape fiber was improved by treating the fiber surface with primer solution. Finally, the fiber was coated with a silicon adhesive layer before being weaved into fabric. The fabric had proven to be a promising candidate for wearable displays with high-visibility outfits. 
(a)
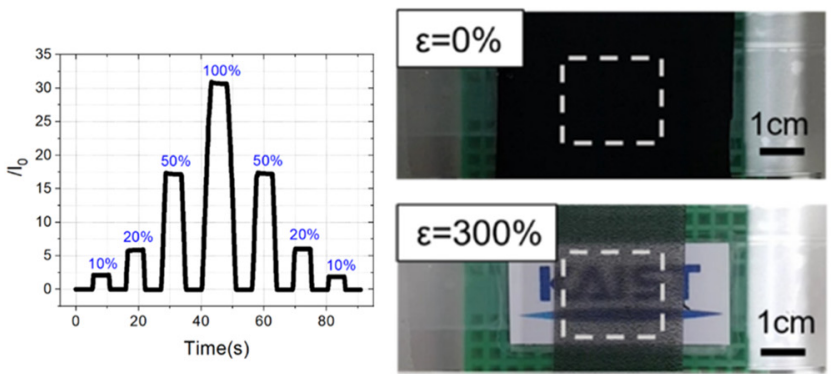

(c)
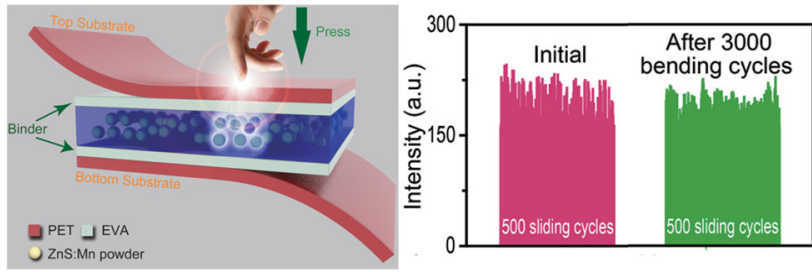

(b)
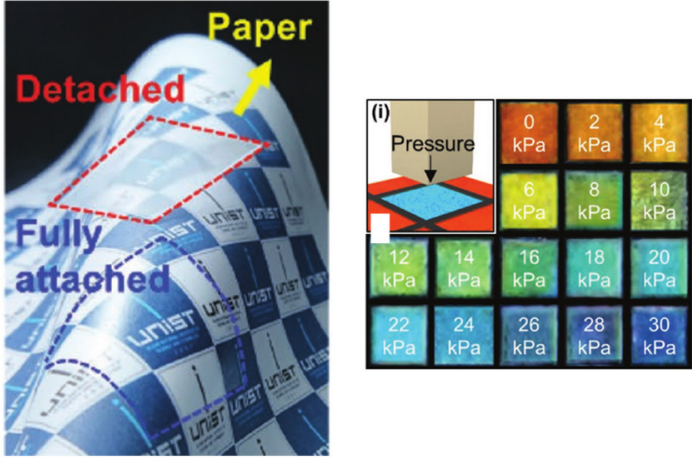

(d)

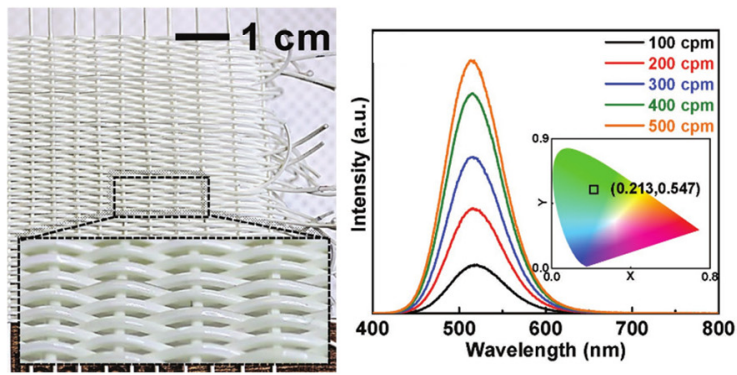

Figure 7. (a) Optical tactile device builds based on CNTs embedded in Ecoflex film [131]. (b) Adaptable and wearable photonic sensor based on shape-memory/responsive cellulose [132].

(c) Pressure mapping of personal handwriting device based on chemiluminescence [133]. (d) Selfpower light-emitting fabric [134].

Table 5. Comparative of the recent optical-based sensor.

\begin{tabular}{|c|c|c|c|c|c|}
\hline Material & Structure & Application & Sensitivity & Advantage & Ref. \\
\hline $\begin{array}{c}\text { poly(MAA-co- } \\
\text { EDMA) } \\
1\end{array}$ & Monolithic Column & $\begin{array}{l}\text { Detection and } \\
\text { quantification of } \\
\text { endogenous }\end{array}$ & $\mathrm{N} / \mathrm{A}$ & $\begin{array}{l}\text { No power source } \\
\text { required }\end{array}$ & [135] \\
\hline PDMS/ZnS:Mn & $\begin{array}{l}\text { Multi array/ } \\
\text { Pyramid }\end{array}$ & Pressor sensor & $0.037 \sim 6 \mathrm{MPa}^{-1}$ & $\begin{array}{l}\text { No power source } \\
\text { required, } \\
\text { high accuracy }\end{array}$ & [136] \\
\hline $\mathrm{CaZn}_{1-\mathrm{x}} \mathrm{Mn}_{\mathrm{x}} \mathrm{OS}$ & Solid state & Color manipulation & $\mathrm{N} / \mathrm{A}$ & $\begin{array}{l}\text { High accuracy, } \\
\text { good sensitivity }\end{array}$ & [137] \\
\hline CaZnOS: $\mathrm{Nd}^{3+} /$ epoxy & Composite disk & Force sensing & $\begin{array}{l}0 \sim 1000 \mathrm{~N} \\
\text { (Unknow } \\
\text { minimum) }\end{array}$ & $\begin{array}{l}\text { High accuracy, } \\
\text { good sensitivity, } \\
\text { fast respond time }\end{array}$ & [138] \\
\hline $\begin{array}{c}\mathrm{Ca}_{2} \mathrm{Nb}_{2} \mathrm{O}_{\mathrm{x}}: \mathrm{Pr}^{3+} \\
\mathrm{PVA}^{2}\end{array}$ & Pellets & Stress sensor & $\mathrm{N} / \mathrm{A}$ & High accuracy & [139] \\
\hline $\begin{array}{l}\text { Ecoflex-ZnS } \\
\text { PAM }^{3}-\mathrm{LiCl}\end{array}$ & Planar & Pressor sensor & $\mathrm{N} / \mathrm{A}$ & $\begin{array}{l}\text { Stretchability, } \\
\text { high accuracy }\end{array}$ & [140] \\
\hline Electroluminescent & Fiber & $\begin{array}{l}\text { Brain-interfaced } \\
\text { communication }\end{array}$ & $\mathrm{N} / \mathrm{A}$ & $\begin{array}{l}\text { Stretchability, } \\
\text { can show three color }\end{array}$ & [141] \\
\hline $\begin{array}{c}\text { ZnS } \\
\text { PDMS }\end{array}$ & Planar & Stress sensor & $\mathrm{N} / \mathrm{A}$ & Stretchable & [142] \\
\hline
\end{tabular}

${ }^{1}$ Poly(MAA-co-EDMA): poly(methacrylic acid-co-ethylene dimethacrylate). ${ }^{2}$ PVA: Polyvinyl Alcohol. ${ }^{3}$ PAM: Polyacrylamide.

\section{Applications}

To date, studies on most sensor devices have been studied to provide more functionality, higher sensitivity, and better wearability. The most common application field for tactile sensors is motion sensors, and new devices, such as multi-pixel structures, are being 
developed to offer high sensitivity and wearability. In addition, the tactile devices can be applied to medical monitoring equipment and artificial intelligence devices using output signals from tactile sensor systems. Furthermore, recently developed tactile devices can distinguish external impact forces, and generate unique signals due to their high sensitivity. This improved performance increases the applicability of tactile sensor devices to other applications in the future, as they serve as both power and signal sources.

\subsection{Motion Sensing-Robotic}

Detecting motion changes are the most representative application field of tactile sensors, and many studies are being conducted to achieve high sensitivity and a wide measurement range of devices. Recently, to introduce not only high sensitivity but also selfpower, a device having two or more operating principles has been developed. As a specific example, a self-powered hybrid sensor that combines a piezoelectric and a triboelectric effect has been proposed to enable operation in a wide measurement range with high sensitivity. Yu et al. presented a hybrid sensor to detect physiological movement based on the contact-separation mode to combine piezo- and triboelectric effects (Figure 8a) [143]. With the external force applied to the device, the output signals are generated by the contactseparation process. The micro-frustum-arrays structure on the two friction layers consisted of P(VDF-TrFE), and lead zirconate titanate (PZT) membranes that have outstanding piezoelectric constants. The hybrid device showed stable piezo- and triboelectric effects under various frequencies, a large number of cycles, and humidity conditions. It also displayed good flexibility and conformal contact with irregular skin surfaces, as the elastic PDMS is used as the primary material. Li et al. proposed a smart self-power tactile device that can both detect a tiny applied pressure, and show the difference between the hardness of various contact materials (Figure 8b) [144]. By distinguishing the shape change of the current peaks, it is possible for the tactile device to create artificial skin that incorporates the feeling of the touched object. In detail, the single electrode unit acts as a contact sensor, while the two-electrode unit plays a key role in guiding the pressure. Thus, the structure of this device makes it capable of correctly identifying complex information from foreign impacts.

When the number of pixels is increased to make a high-resolution tactile sensor, the number of addressing lines increases, while the speed of signal processing decreases. To overcome this, Wang et al. have proposed a self-powered device with a new pattern for a high-resolution electrode based on a single electrode triboelectric generator (Figure 8c) [145]. These cross-type triboelectric sensor matrices can significantly reduce the number of addressing lines from $(m \times n)$ to $(m+n)$ for a shorter measurement period for real-time mapping. Jin et al. reported a thermoelectric device that can emit different electrical signals depending on the angles of the foundation formed on the sensor (Figure 8d) [146]. Specifically, the charge and voltage generated by the equipment are independent of the frequency, and show different output values according to various movements of the finger. In addition, electrical signals generated according to movement in different joints appear differently. Therefore, using the principle of this device, it may be applied as a promising sensor in the robotics field of motion control.

The device based on fiber and fabric also seems to have promising potential for wearables sensors [147]. Shin et al. reported a mechanically strong PVDF fiber using "dry-jet wet spinning" method (Figure 8e) [148]. The authors mentioned the method to be similar to "wet-spinning" with the spinneret being outside the coagulation bath. The fabricated fiber's properties are good enough to be used with a sewing machine. The stitching of PVDF threads enables has given advantages as flexible pattern design and form factors for motion sensing. It is also mentioned that the sensor has a very broad range of detecting capability (from $326 \mathrm{~Pa}$ to $326 \mathrm{kPa}$ ). Yang et al. developed a super-stretchable and structure-designable liquid-metal-based TENG (Figure 8f) [149]. The liquid metal Galinstan was injected into silicone rubber to form a flexible electrode. The rubber in the device structure plays the role of encapsulation and triboelectric material. This design has 
provided a large advantage in stretchability and functional up to $300 \%$ strain. Lastly, the sensor has been demonstrated to generate energy from human mechanical activity.

(a)
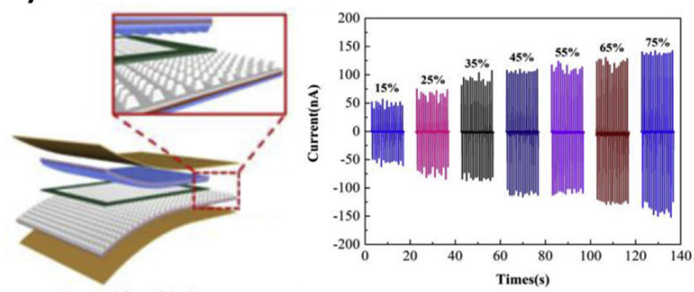

(c)

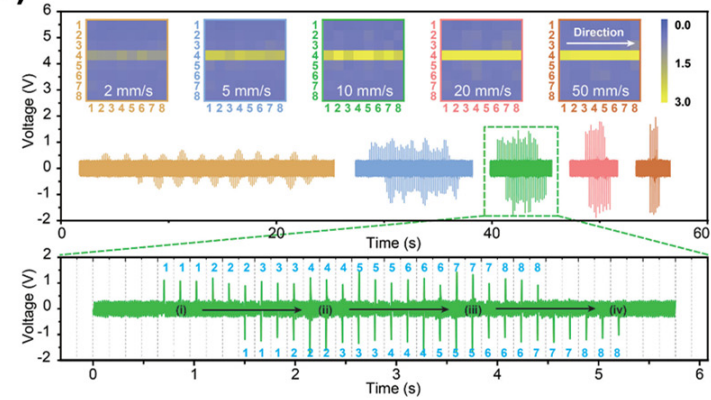

(e)

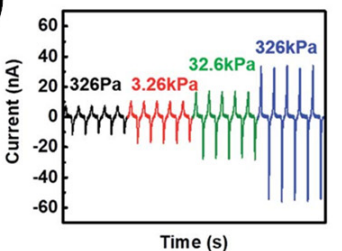

Time (s)

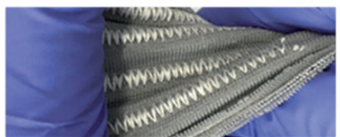

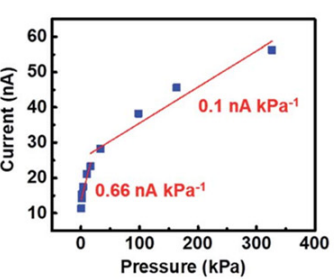

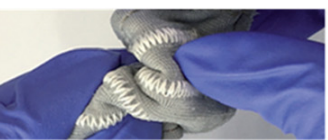

(b)

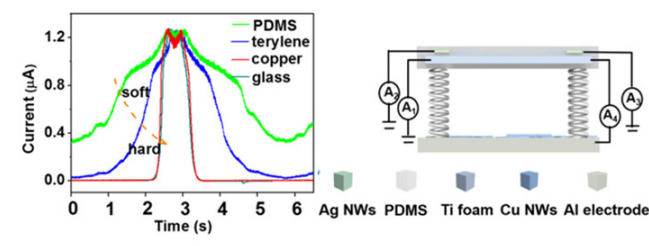

(d)
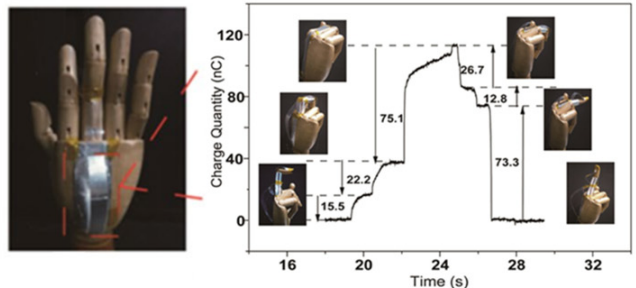

(f)

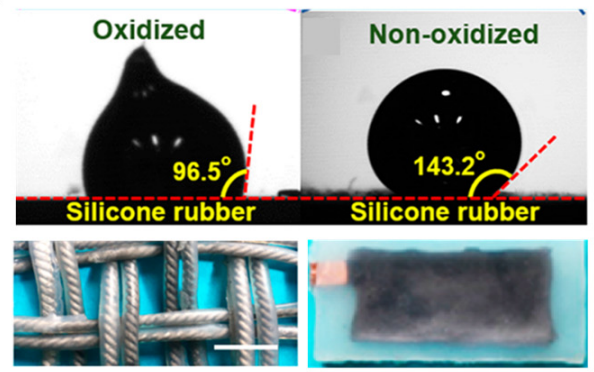

Figure 8. (a) Motion sensor constructs from $\mathrm{Cu}$ and $\mathrm{P}(\mathrm{VDF}-\mathrm{TrFE})$ nanofiber pyramid electrode [143]. (b) Dual-mode triboelectric nanogenerator for location, pressure, and motion [144]. (c) Self-powered, high-resolution, and pressure-sensitive single electrode triboelectric generator based on singleelectrode triboelectric generators that enable real-time tactile mapping [145]. (d) Triboelectric combined with artificial finger as a self-power sensing system [146]. (e) PVDF fiber thread sewed into a fabric using a sewing machine acted as TENG [148]. (f) Liquid-metal Galinstan electrode in silicone rubber triboelectric material for super stretchable TENG [149].

\subsection{Health Care}

Tactile detection sensors are also applied to health care monitoring applications, including e-skin sensors, due to their high sensitivity. Since this field requires higher sensitivity than other applications, the piezoresistive and piezocapacitive effects should be used, rather than the piezoelectric and triboelectric principles of operation. However, the biggest weakness of devices using piezoresistive and piezocapacitive effects is that the signal-to-noise ratio (SNR) is generally low. To overcome this disadvantage, Cai et al. manufactured a 3D sensor substrate with carbon nanotubes attached to nickel foam using chemical vapor deposition (Figure 9a) [150]. The 3D micro-architectural carbon-based percolation network can provide sponge properties as well as electronic conductivity, which can detect large deformation. Moreover, the 3D carbon-based tactile foam sensor 
shows both high stretching properties and SNR, and high deformation resistance due to external stimulation.

(a)

(c)
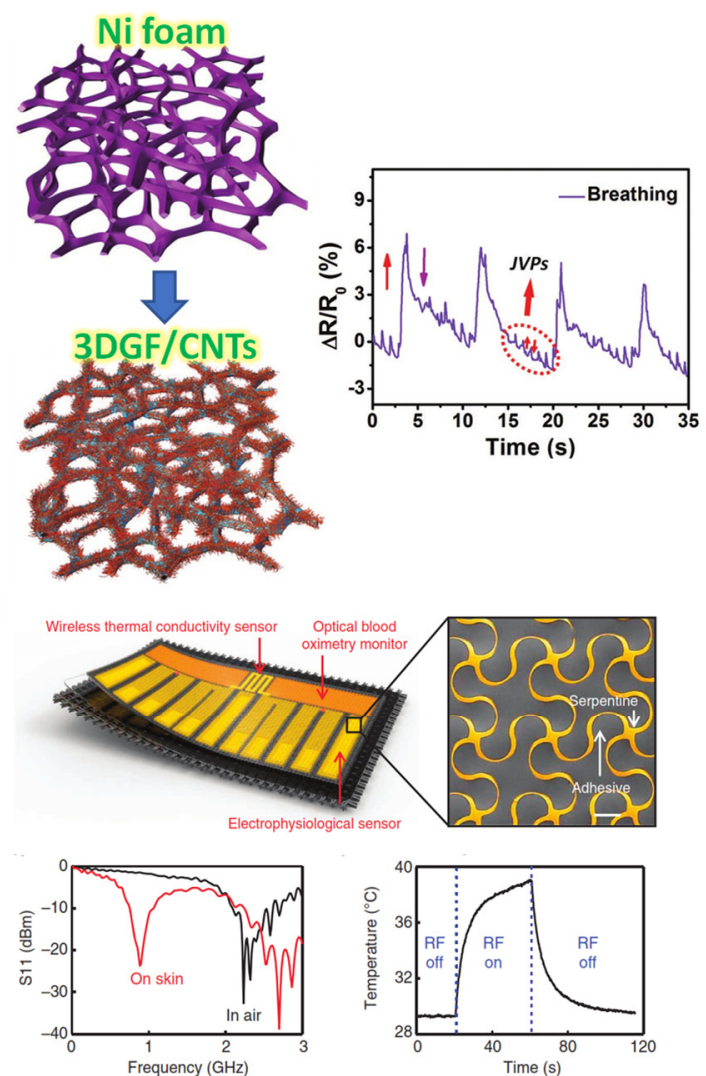

(b)

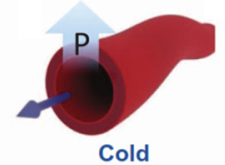

vasoconstriction
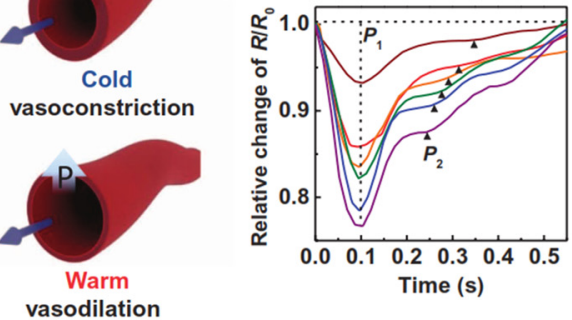

(d)
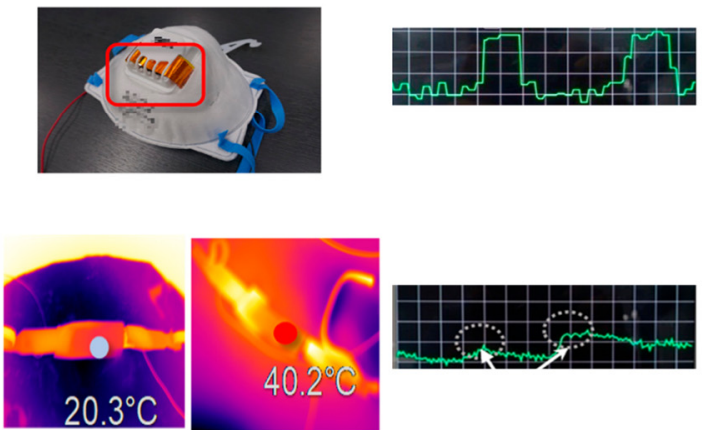

Figure 9. (a) All-carbon collaborative nanoarchitectures for epidermal sensors [150]. (b) E-skin tactile device for simultaneous monitoring of temperature and artery pulse pressure [151]. (c) Rugged and breathable electronics with an adherent composite substrate for transcutaneous monitoring [152]. (d) A triple-mode flexible e-skin sensor for wearable applications [153].

Park et al. developed e-skin using graphene and PVDF composite by imitating the epidermis-skin microstructure of human skin (Figure 9b) [151]. When attached to the skin of the wrist, the interlocked e-skin may react to both temperature and arterial pulse pressure. In addition, the e-skin may recognize the time and space of static or dynamic tactile stimulation according to changes in arterial stiffness, pulse wave velocity (PWV), and reflected waves.

In e-skin applications that can measure health status in real-time, improving the flexibility of the device is an important factor for high adhesion. Jang et al. suggested a way to integrate elastic fabrics and thin electronic modules with flexible thermal and optical blood oxygen measurement and physiological monitoring systems (Figure 9c) [152]. Due to its high adhesion, this system both reacts sensitively to signals from the skin, even in hairy areas, and can be reused through detachment. In addition, the ultralow modulus silicone (UL-Sil) substrate used in the device showed good stability with respect to the electrode during stretching, while the finite element analysis showed little stress at the maximum strain of $60 \%$. In addition, Kim et al. suggested a flexible reading integrated circuit that combines piezoresistive, piezoelectricity, and pyroelectric using graphene and PVDF as a substrate (Figure 9d) [153]. The flexible module operates by obtaining the desired signal by selecting an operation mode for the desired body part.

\subsection{Artificial Intelligence}

Recently, tactile sensors have been applied to artificial intelligence (AI) on external stimuli of artificial intelligence. Zhou et al. developed a flexible pressure sensor with a very 
short reaction and recovery time using the high surface area of the mesh substrate, and used it as a device to analyze the motion characteristics of the human hand (Figure 10a) [154]. Furthermore, it was also applied as a sensor capable of detecting the pressure of sound by using the principle that as the applied pressure increases, the current generated by the device increases. Data was collected based on a change in current according to the sound pressure collected by the device and then applied to AI training for song recognition.

(a)

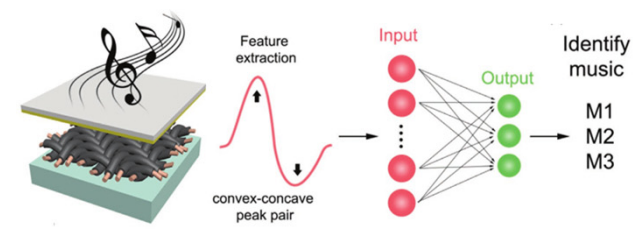

(c)

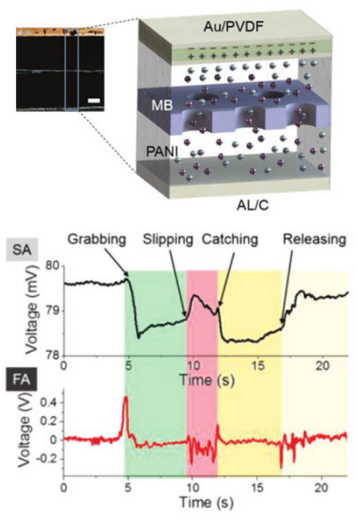

(b)

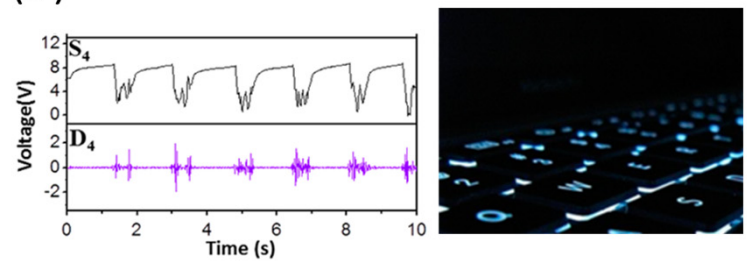

(d)

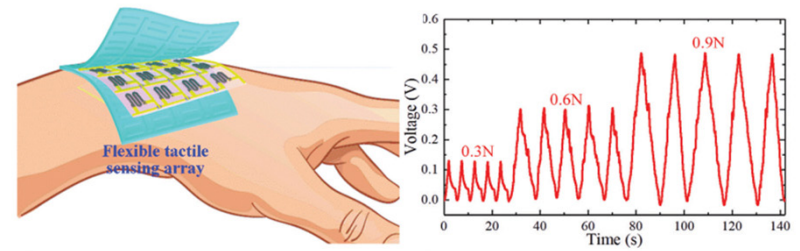

Figure 10. (a) A hybrid array on copper mesh sound sensor for artificial intelligence [154]. (b) Keystroke tactile for human-machine interface [155]. (c) Self-power sensor mimicking slow/fastadapting cutaneous mechanoreceptors [156] (d) Highly flexible tactile sensor with an interlocked truncated sawtooth structure based stretchable rubber composites [157].

Chen et al. proposed an intelligent keyboard device capable of identification according to a user's touch (Figure 10b) [155]. The keyboard converts the typing operation into an electrical signal pattern, and then distinguishes the identity of the user according to the resistance change through a combined resistor. In addition, the electrical signal also records specific dynamic changes occurring during the input process for higher-level verification. Meanwhile, Chun et al. proved the correlation with substances in contact with human hands (Figure 10c) [156]. Specifically, by introducing an ion film into a piezoelectric device, the difference in reaction rate and the magnitude of the output signals were patterned using the principle of ion movement according to the injection of stimulation in the neuron system. As a result, the device formed a unique pattern, even in complex stimuli, such as gripping operation, sliding operation, and rubbing operation.

Furthermore, a tactile sensor having a biomimetic structure is being developed to collect response signals for various external stimuli. Wa et al. presented a highly flexible tactile sensor with an interlocked truncated sawtooth structure (Figure 10d) [157]. This structure allows the device to convert external pressure to internal tensile stress, which is the sensing mechanism of the graphene pattern. The graphene layer generates a small amount of voltage according to the conversion generated when the device system is pressurized. By using the signal change of the output voltage generated by this device, it is possible to distinguish the pattern of the touch applied to the device.

Some excellent structures in the natural environment can provide excellent response signals from the outside to the host, such as the ubiquitous tactile fur of the insect [158]. Li et al. mimicked the insect's hair structure and function using spinal nanostructured 
zinc oxide fine particles (Figure 11a) [159]. Due to its unique structure that simulates insect fur, this device both offers fast response time and high sensitivity to external stimuli and provides excellent mechanical resilience [160,161]. Li et al. also produced a micropatterned substrate similar to the structure of the lotus leaf and applied it as a tactile sensor (Figure 11b) [162]. Specifically, polystyrene microparticles were combined to the dielectric between the two electrodes of the device to form a sensor that exhibited high sensitivity to external stimuli, such as bending, stretching, and pressure.

(a)
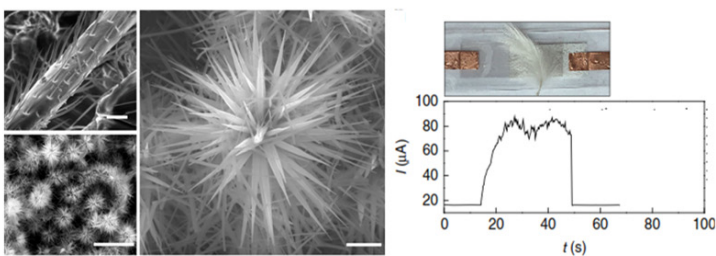

(c)
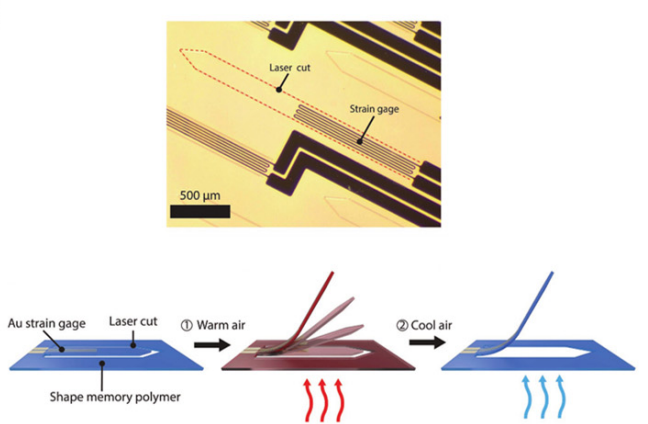

(b)

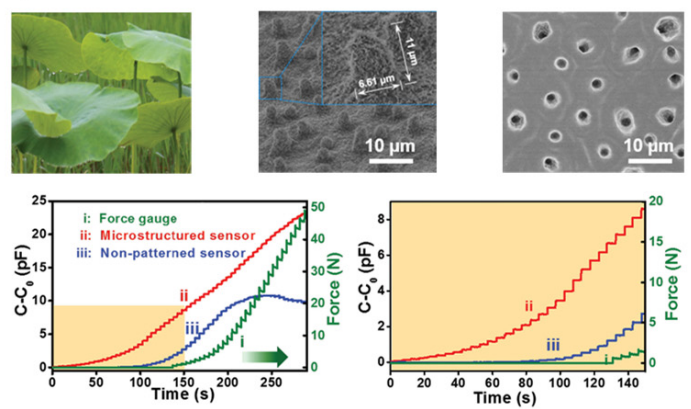

(d)
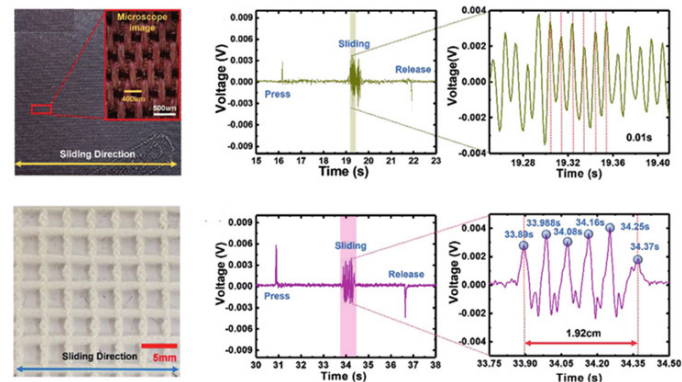

Figure 11. (a) A tactile sensor inspired by bristles or tactile hairs [159]. (b) Artificial intelligence based on the structure of the lotus leaf [162]. (c) Multimodal Electronic Whiskers [163]. (d) Tactile sensing system mimicking human tactile [164].

A scalable method for the 3D assembly of arrays that can be reconfigured postfabrication has been demonstrated by Reeder et al. (Figure 11c) [163]. The adaptive electronic whiskers can sense a wide variety of stimuli using a single strain gauge. The e-whiskers are able to mimic the sensing capabilities of human feeling including proximity, applied force, and material texture, roughness. The sensor structure has allowed it to contain a very large number of pixels with high sensitivity. It has been proven that the device can even detect a human's fingerprint. Kim et al. reported an artificial tactile sensor that can mimic the feeling of skin on different surface materials (Figure 11d) [164]. The human was sensed based on the piezoelectric multiarray system and the deep learning process. The authors chose a simple piezoelectric sensor to create the signal for the deep learning process. The systematic approach to mimic human tactile cognition was adopted, and thus make the sensor behave similarly to a human. From this study, we can see that tactile sensors can achieve remarkable results when combined with a good analysis system, thus becoming an outstanding candidate for development.

\section{Conclusions and Outlook}

In this review, we have investigated the tactile sensor and reviewed its development. Overall, the four major working mechanisms of piezoresistive, piezocapacitive, piezoelectric, and triboelectric were investigated. Their applications to touching sensors showed excellent working performance, and have thus furnished good results in motion sensingrobotic, health care monitoring, and artificial intelligence. In the future, advances in new 
materials, microstructure, and nanostructure can offer great potential for the improvement of sensors. On the other hand, artificial intelligence tactile device has got large achievements in advanced applications, such as behavior studies, or the identification of configurations. Yet, it still has so many promising potentials for further development. These developments can greatly speed up the growth of high technologies and human-machine interface studies.

Author Contributions: The manuscript was written through contributions of all authors. All authors have given approval to the final version of the manuscript. All authors have read and agreed to the published version of the manuscript.

Funding: This research received no external funding.

Institutional Review Board Statement: Not applicable.

Informed Consent Statement: Not applicable.

Data Availability Statement: Not applicable.

Acknowledgments: This work was supported by the Gachon University Research Fund of 2021 (GCU- 202103360001).

Conflicts of Interest: The authors declare no competing financial interest.

\section{References}

1. Sorabji, R. Aristotle on Demarcating the Five Senses. Philos. Rev. 1971, 80, 55-79. [CrossRef]

2. Stevens, J.C.; Green, B.G. Chapter 1-History of Research on Touch. In Pain and Touch; Kruger, L., Ed.; Academic Press: San Diego, CA, USA, 1996; pp. 1-23.

3. Dargahi, J.; Najarian, S. Human tactile perception as a standard for artificial tactile sensing-A review. Int. J. Med. Robot. 2004, 1, 23-35. [CrossRef] [PubMed]

4. Belzile, B.; Birglen, L. Optimal Design of Self-Adaptive Fingers for Proprioceptive Tactile Sensing. J. Mech. Robot. 2017, 9, 051004. [CrossRef]

5. Jeon, S. Flexible Multimodal Sensors for Electronic Skin: Principle, Materials, Device, Array Architecture, and Data Acquisition Method. Proc. IEEE 2019, 107, 2065-2083. [CrossRef]

6. Cosseddu, P. Tactile sensors with integrated piezoelectric polymer and low voltage organic thin-film transistors. In Proceedings of the Sensors, 2014 IEEE, Valencia, Spain, 2-5 November 2014; pp. 1734-1736.

7. Chen, H. Electronic Skins for Healthcare Monitoring and Smart Prostheses. Annu. Rev. Control 2021, 4, 629-650. [CrossRef]

8. Weerasinghe, L.; Chathuranga, D.S. Development and Characterization of a Soft Tactile Sensor Array Used for Parallel Grippers. In Proceedings of the MERCon 2018: 4th International Multidisciplinary Engineering Research Conference, Moratuwa, Sri Lanka, 30 May-1 June 2018; pp. 102-107.

9. Tiwana, M.I. A review of tactile sensing technologies with applications in biomedical engineering. Sens. Actuat. A Phys. 2012, 179, 17-31. [CrossRef]

10. Dahiya, R.S. Directions Toward Effective Utilization of Tactile Skin: A Review. IEEE Sens. J. 2013, 13, 4121-4138. [CrossRef]

11. Almassri, A.M. Pressure Sensor: State of the Art, Design, and Application for Robotic Hand. J. Sens. 2015, 2015, 846487. [CrossRef]

12. Fu, X. A high-resolution, ultrabroad-range and sensitive capacitive tactile sensor based on a CNT/PDMS composite for robotic hands. Nanoscale 2021, 13, 18780-18788. [CrossRef]

13. Nguyen, T.D. Highly sensitive flexible proximity tactile array sensor by using carbon micro coils. Sens. Actuat. A Phys. 2017, 266, 166-177. [CrossRef]

14. Liu, H. Lightweight, Superelastic, and Hydrophobic Polyimide Nanofiber / MXene Composite Aerogel for Wearable Piezoresistive Sensor and Oil/Water Separation Applications. Adv. Funct. Mater. 2021, 31, 2008006. [CrossRef]

15. Wu, J. Extremely Deformable, Transparent, and High-Performance Gas Sensor Based on Ionic Conductive Hydrogel. ACS Appl. Mater. Interfaces 2019, 11, 2364-2373. [CrossRef]

16. Wang, T. A Self-Healable, Highly Stretchable, and Solution Processable Conductive Polymer Composite for Ultrasensitive Strain and Pressure Sensing. Adv. Funct. Mater. 2018, 28, 1705551. [CrossRef]

17. Han, S. Dual Conductive Network Hydrogel for a Highly Conductive, Self-Healing, Anti-Freezing, and Non-Drying Strain Sensor. ACS Appl. Polym. Mater. 2020, 2, 996-1005. [CrossRef]

18. Takei, K. Highly sensitive electronic whiskers based on patterned carbon nanotube and silver nanoparticle composite films. Proc. Natl. Acad. Sci. USA 2014, 111, 1703-1707. [CrossRef]

19. Zang, Y. A Dual-Organic-Transistor-Based Tactile-Perception System with Signal-Processing Functionality. Adv. Mater. 2017, 29, 1606088. [CrossRef]

20. Choi, E. Highly Sensitive Tactile Shear Sensor Using Spatially Digitized Contact Electrodes. Sensors 2019, 19, 1300. [CrossRef] [PubMed] 
21. Choi, D. A Highly Sensitive Tactile Sensor Using a Pyramid-Plug Structure for Detecting Pressure, Shear Force, and Torsion. Adv. Mater. Technol. 2018, 4, 1800284. [CrossRef]

22. Kweon, O.Y. Wearable high-performance pressure sensors based on three-dimensional electrospun conductive nanofibers. NPG Asia Mater. 2018, 10, 540-551. [CrossRef]

23. $\mathrm{Wu}, \mathrm{C}$. A new approach for an ultrasensitive tactile sensor covering an ultrawide pressure range based on the hierarchical pressure-peak effect. Nanoscale Horiz. 2020, 5, 541-552. [CrossRef]

24. Zhu, L. Development of Fully Flexible Tactile Pressure Sensor with Bilayer Interlaced Bumps for Robotic Grasping Applications Micromachines 2020, 11, 770. [CrossRef]

25. Alfadhel, A. A Magnetoresistive Tactile Sensor for Harsh Environment Applications. Sensors 2016, 16, 650. [CrossRef] [PubMed]

26. Huang, K.-H. A tactile sensing array integrated with tension sensor for continuously monitoring blood pulse waves. Microelectron. Eng. 2019, 218, 111132. [CrossRef]

27. Kim, Y. A bioinspired flexible organic artificial afferent nerve. Science 2018, 360, 998-1003. [CrossRef]

28. Valkanis, A. Efficient Resource Allocation in Tactile-Capable Ethernet Passive Optical Healthcare LANs. IEEE Access 2020, 8 , 52981-52995. [CrossRef]

29. Gupta, R. Tactile-Internet-Based Telesurgery System for Healthcare 4.0: An Architecture, Research Challenges, and Future Directions. IEEE Netw. 2019, 33, 22-29. [CrossRef]

30. Wong, E. Tactile internet capable passive optical LAN for healthcare. In Proceedings of the 2016 21st OptoElectronics and Communications Conference (OECC) Held Jointly with 2016 International Conference on Photonics in Switching (PS), Niigata, Japan, 3-7 July 2016; pp. 1-3.

31. Ntagios, M. Robotic Hands with Intrinsic Tactile Sensing via 3D Printed Soft Pressure Sensors. Adv. Intell. Syst. 2020, 2, 1900080. [CrossRef]

32. Navaraj, W.; Dahiya, R. Fingerprint-Enhanced Capacitive-Piezoelectric Flexible Sensing Skin to Discriminate Static and Dynamic Tactile Stimuli. Adv. Intell. Syst. 2019, 1, 1900051. [CrossRef]

33. Jin, T. Triboelectric nanogenerator sensors for soft robotics aiming at digital twin applications. Nat. Commun. 2020, 11, 5381. [CrossRef] [PubMed]

34. Hidalgo-López, J.A. New Approaches for Increasing Accuracy in Readout of Resistive Sensor Arrays. IEEE Sens. J. 2017, 17, 2154-2164. [CrossRef]

35. Vidal-Verdú, F. Three Realizations and Comparison of Hardware for Piezoresistive Tactile Sensors. Sensors 2011, 11, 3249-3266. [CrossRef] [PubMed]

36. Drimus, A. Design of a flexible tactile sensor for classification of rigid and deformable objects. Robot. Auton. Syst. 2014, 62,3-15. [CrossRef]

37. Fiorillo, A.S. Theory, technology and applications of piezoresistive sensors: A review. Sens. Actuat. A Phys. 2018, 281, 156-175 [CrossRef]

38. Cookson, J.W. Theory of the Piezo-Resistive Effect. Phys. Rev. 1935, 47, 194-195. [CrossRef]

39. Martin, D.T. A Micromachined Dual-Backplate Capacitive Microphone for Aeroacoustic Measurements. J. Microelectromech. Syst. 2007, 16, 1289-1302. [CrossRef]

40. Huang, J. Piezocapacitive effect of a sandwich structure in a microfabricated cantilever. In Proceedings of the 2010 IEEE 23 rd International Conference on Micro Electro Mechanical Systems (MEMS), Hong Kong, China, 24-28 January 2010; pp. 564-567.

41. Gautschi, G. Piezoelectric Sensorics; Springer: Berlin/Heidelberg, Germany, 2002; 264p.

42. Birkholz, M. Crystal-field induced dipoles in heteropolar crystals II: Physical significance. Phys. B Condens. Matter 1995, 96, 333-340. [CrossRef]

43. Moheimani, S.O.R.; Fleming, A.J. Fundamentals of Piezoelectricity. In Piezoelectric Transducers for Vibration Control and Damping; Springer: London, UK, 2006; pp. 9-35.

44. Niu, S.; Wang, Z.L. Theoretical systems of triboelectric nanogenerators. Nano Energy 2015, 14, 161-192. [CrossRef]

45. Ye, B.U. Electrospun ion gel nanofibers for flexible triboelectric nanogenerator: Electrochemical effect on output power. Nanoscale 2015, 7, 16189-16194. [CrossRef]

46. Pan, S.; Zhang, Z. Fundamental theories and basic principles of triboelectric effect: A review. Friction 2019, 7, 2-17. [CrossRef]

47. Cheng, T. The Current Development and Future Outlook of Triboelectric Nanogenerators: A Survey of Literature. Adv. Mater. Technol. 2019, 4, 1800588. [CrossRef]

48. Shao, J. Theoretical modeling of triboelectric nanogenerators (TENGs). J. Appl. Phys. 2020, 128, 111101. [CrossRef]

49. Arthurs, D.; Ziada, S. Flow-excited acoustic resonances of coaxial side-branches in an annular duct. J. Fluids Struct. 2009, 25, 42-59. [CrossRef]

50. Peng, S. Multimodal Capacitive and Piezoresistive Sensor for Simultaneous Measurement of Multiple Forces. ACS Appl. Mater. Interfaces 2020, 12, 22179-22190. [CrossRef] [PubMed]

51. Cao, M. CB Nanoparticles Optimized 3D Wearable Graphene Multifunctional Piezoresistive Sensor Framed by Loofah Sponge. ACS Appl. Mater. Interfaces 2020, 12, 36540-36547. [CrossRef]

52. Li, Y. Poisson Ratio and Piezoresistive Sensing: A New Route to High-Performance 3D Flexible and Stretchable Sensors of Multimodal Sensing Capability. Adv. Funct. Mater. 2016, 26, 2900-2908. [CrossRef] 
53. Pang, C. A flexible and highly sensitive strain-gauge sensor using reversible interlocking of nanofibres. Nat. Mater. 2012, 11, 795-801. [CrossRef]

54. Damilano, A. Commercial tactile sensors for hand exoskeletons: Practical considerations for ultra-low cost and very-low complexity read-out. IEEE Instrum. Meas. Mag. 2016, 19, 49-56. [CrossRef]

55. Engel, J. Polymer micromachined multimodal tactile sensors. Sens. Actuat. A Phys. 2005, 117, 50-61. [CrossRef]

56. Engel, J. Strain sensitivity enhancement of thin metal film strain gauges on polymer microscale structures. Appl. Phys. Lett. 2006, 89, 221907. [CrossRef]

57. Rogers, J.A. Materials and Mechanics for Stretchable Electronics. Science 2010, 327, 1603-1607. [CrossRef]

58. Coskun, M.B. Detecting Subtle Vibrations Using Graphene-Based Cellular Elastomers. ACS Appl. Mater. Interfaces 2017, 9, 11345-11349. [CrossRef]

59. Shang, S. Piezoresistive strain sensing of carbon black / silicone composites above percolation threshold. Rev. Sci. Instrum. 2016, 87, 123910. [CrossRef] [PubMed]

60. Kumar, S.S.; Pant, B.D. Polysilicon thin film piezoresistive pressure microsensor: Design, fabrication and characterization Microsyst. Technol. 2015, 21, 1949-1958. [CrossRef]

61. Zhang, S. Piezoresistive silicon nanowire based nanoelectromechanical system cantilever air flow sensor. Appl. Phys. Lett. 2012, 100, 023111. [CrossRef]

62. Zang, X. Unprecedented sensitivity towards pressure enabled by graphene foam. Nanoscale 2017, 9, 19346-19352. [CrossRef]

63. Khan, F.A. Silver Nanoflower Decorated Graphene Oxide Sponges for Highly Sensitive Variable Stiffness Stress Sensors. Small 2018, 14, 1800549. [CrossRef]

64. Liu, W. Piezoresistive Pressure Sensor Based on Synergistical Innerconnect Polyvinyl Alcohol Nanowires/Wrinkled Graphene Film. Small 2018, 14, 1704149. [CrossRef]

65. Wang, X. Silk-Molded Flexible, Ultrasensitive, and Highly Stable Electronic Skin for Monitoring Human Physiological Signals. Adv. Mater. 2014, 26, 1336-1342. [CrossRef] [PubMed]

66. Lee, S. A transparent bending-insensitive pressure sensor. Nat. Nanotechol. 2016, 11, 472-478. [CrossRef]

67. Wang, L. PDMS/MWCNT-based tactile sensor array with coplanar electrodes for crosstalk suppression. Microsyst. Nanoeng. 2016, 2, 16065. [CrossRef] [PubMed]

68. Hammock, M.L. 25th anniversary article: The evolution of electronic skin (e-skin): A brief history, design considerations, and recent progress. Adv. Mater. 2013, 25, 5997-6038. [CrossRef]

69. Elsayes, A. Plant-Based Biodegradable Capacitive Tactile Pressure Sensor Using Flexible and Transparent Leaf Skeletons as Electrodes and Flower Petal as Dielectric Layer. Adv. Sustain. Syst. 2020, 4, 2000056. [CrossRef]

70. James, S.; Contractor, R. Study on Nature-inspired Fractal Design-based Flexible Counter Electrodes for Dye-Sensitized Solar Cells Fabricated using Additive Manufacturing. Sci. Rep. 2018, 8, 17032. [CrossRef] [PubMed]

71. Beck, C.B. An Introduction to Plant Structure and Development: Plant Anatomy for the Twenty-First Century, 2nd ed.; Cambridge University Press: Cambridge, UK, 2010.

72. Bae, K. Large-Area, Crosstalk-Free, Flexible Tactile Sensor Matrix Pixelated by Mesh Layers. ACS Appl. Mater. Interfaces 2021, 13, 12259-12267. [CrossRef]

73. Mannsfeld, S.C. Highly sensitive flexible pressure sensors with microstructured rubber dielectric layers. Nat. Mater. 2010, 9 , 859-864. [CrossRef]

74. Mi, Y. Micromolding of PDMS scaffolds and microwells for tissue culture and cell patterning: A new method of microfabrication by the self-assembled micropatterns of diblock copolymer micelles. Polymer 2006, 47, 5124-5130. [CrossRef]

75. Balaban, N.Q. Force and focal adhesion assembly: A close relationship studied using elastic micropatterned substrates. Nat. Cell Biol. 2001, 3, 466-472. [CrossRef]

76. Boutry, C.M. A hierarchically patterned, bioinspired e-skin able to detect the direction of applied pressure for robotics. Sci. Robot. 2018, 3, eaau6914. [CrossRef]

77. Kamolz, L.P.; Lumenta, D.B. Dermal Replacements in General, Burn, and Plastic Surgery: Tissue Engineering in Clinical Practice; Springer: Vienna, Austria, 2013.

78. Maiolino, P. A Flexible and Robust Large Scale Capacitive Tactile System for Robots. IEEE Sens. J. 2013, 13, 3910-3917. [CrossRef]

79. Pyo, S. Flexible, Transparent, Sensitive, and Crosstalk-Free Capacitive Tactile Sensor Array Based on Graphene Electrodes and Air Dielectric. Adv. Electron. Mater. 2018, 4, 1700427. [CrossRef]

80. An, B.W. Transparent and flexible fingerprint sensor array with multiplexed detection of tactile pressure and skin temperature. Nat. Commun. 2018, 9, 2458. [CrossRef]

81. Lei, K.F. Development of a flexible PDMS capacitive pressure sensor for plantar pressure measurement. Microelectron. Eng. 2012, 99, 1-5. [CrossRef]

82. Lee, H. Normal and Shear Force Measurement Using a Flexible Polymer Tactile Sensor With Embedded Multiple Capacitors. J. Microelectromech. Syst. 2008, 17, 934-942.

83. Wan, Y. A Highly Sensitive Flexible Capacitive Tactile Sensor with Sparse and High-Aspect-Ratio Microstructures. Adv. Electron. Mater. 2018, 4, 1700586. [CrossRef]

84. Nie, B. Microfluidic tactile sensors for three-dimensional contact force measurements. Lab. Chip 2014, 14, 4344-4353. [CrossRef] [PubMed] 
85. Zhao, X. Flexible, Stretchable and Wearable Multifunctional Sensor Array as Artificial Electronic Skin for Static and Dynamic Strain Mapping. Adv. Electron. Mater. 2015, 1, 1500142. [CrossRef]

86. Fu, Y. Design, fabrication and testing of piezoelectric polymer PVDF microactuators. Smart Mater. Struct. 2006, 15, 141-146. [CrossRef]

87. Wang, Z. Flexible and Washable Poly(Ionic Liquid) Nanofibrous Membrane with Moisture Proof Pressure Sensing for Real-Life Wearable Electronics. ACS Appl. Mater. Interfaces 2019, 11, 27200-27209. [CrossRef] [PubMed]

88. Jeong, C.K. Lead-Free Perovskite Nanowire-Employed Piezopolymer for Highly Efficient Flexible Nanocomposite Energy Harvester. Small 2018, 14, 1704022. [CrossRef]

89. Jiang, J. Flexible Piezoelectric Pressure Tactile Sensor Based on Electrospun BaTiO3/Poly(vinylidene fluoride) Nanocomposite Membrane. ACS Appl. Mater. Interfaces 2020, 12, 33989-33998. [CrossRef] [PubMed]

90. Chen, X. High-Performance Piezoelectric Nanogenerators with Imprinted P(VDF-TrFE)/BaTiO3 Nanocomposite Micropillars for Self-Powered Flexible Sensors. Small 2017, 13, 1604245. [CrossRef]

91. Dagdeviren, C. Conformable amplified lead zirconate titanate sensors with enhanced piezoelectric response for cutaneous pressure monitoring. Nat. Commun. 2014, 5, 4496. [CrossRef] [PubMed]

92. Lin, W. Skin-Inspired Piezoelectric Tactile Sensor Array with Crosstalk-Free Row+Column Electrodes for Spatiotemporally Distinguishing Diverse Stimuli. Avd. Sci. 2021, 8, 2002817. [CrossRef] [PubMed]

93. Deng, W. Cowpea-structured PVDF/ZnO nanofibers based flexible self-powered piezoelectric bending motion sensor towards remote control of gestures. Nano Energy 2019, 55, 516-525. [CrossRef]

94. Zhao, G. Piezoelectric Polyacrylonitrile Nanofiber Film-Based Dual-Function Self-Powered Flexible Sensor. ACS Appl. Mater. Interfaces 2018, 10, 15855-15863. [CrossRef]

95. Zhang, Q. Transparent and Self-Powered Multistage Sensation Matrix for Mechanosensation Application. ACS Nano 2018, 12, 254-262. [CrossRef]

96. Park, D.Y. Self-Powered Real-Time Arterial Pulse Monitoring Using Ultrathin Epidermal Piezoelectric Sensors. Adv. Mater. 2017, 29, 1702308. [CrossRef]

97. Song, H. Lead iodide nanosheets for piezoelectric energy conversion and strain sensing. Nano Energy 2018, 49, 7-13. [CrossRef]

98. Guo, R. A self-powered stretchable sensor fabricated by serpentine PVDF film for multiple dynamic monitoring. Mater. Des. 2019 182, 108025. [CrossRef]

99. Kim, M.-O. Flexible and multi-directional piezoelectric energy harvester for self-powered human motion sensor. Smart Mater. Struct. 2018, 27, 035001. [CrossRef]

100. Pan, C. High-resolution electroluminescent imaging of pressure distribution using a piezoelectric nanowire LED array. Nat. Photonics 2013, 7, 752-758. [CrossRef]

101. Wu, W. Piezoelectricity of single-atomic-layer MoS2 for energy conversion and piezotronics. Nature 2014, 514, 470-474. [CrossRef] [PubMed]

102. Wang, Z.L. Progress in triboelectric nanogenerators as a new energy technology and self-powered sensors. Energy Environ. Sci. 2015, 8, 2250-2282. [CrossRef]

103. Wang, Z. Triboelectric Nanogenerators: Green Energy and Technology; Springer: Cham, Switzerland, 2016; 517p.

104. Wang, P. Complementary Electromagnetic-Triboelectric Active Sensor for Detecting Multiple Mechanical Triggering. Adv. Funct. Mater. 2018, 28, 1705808. [CrossRef]

105. Dong, K. Versatile Core-Sheath Yarn for Sustainable Biomechanical Energy Harvesting and Real-Time Human-Interactive Sensing. Adv. Energ. Mater. 2018, 8, 1801114. [CrossRef]

106. Zhu, M. Technologies toward next generation human machine interfaces: From machine learning enhanced tactile sensing to neuromorphic sensory systems. Appl. Phys. Rev. 2020, 7, 031305. [CrossRef]

107. Nguyen, V.; Yang, R. Effect of humidity and pressure on the triboelectric nanogenerator. Nano Energy 2013, 2, 604-608. [CrossRef]

108. Chen, X. Waterproof and stretchable triboelectric nanogenerator for biomechanical energy harvesting and self-powered sensing. Appl. Phys. Lett. 2018, 112, 203902. [CrossRef]

109. Dong, K. A Stretchable Yarn Embedded Triboelectric Nanogenerator as Electronic Skin for Biomechanical Energy Harvesting and Multifunctional Pressure Sensing. Adv. Mater. 2018, 30, 1804944. [CrossRef]

110. Yang, Y. Single-Electrode-Based Sliding Triboelectric Nanogenerator for Self-Powered Displacement Vector Sensor System. ACS Nano 2013, 7, 7342-7351. [CrossRef]

111. He, W. Boosting output performance of sliding mode triboelectric nanogenerator by charge space-accumulation effect. Nat. Commun. 2020, 11, 4277. [CrossRef]

112. Zhang, B. Self-Powered Acceleration Sensor Based on Liquid Metal Triboelectric Nanogenerator for Vibration Monitoring. ACS Nano 2017, 11, 7440-7446. [CrossRef]

113. Wen, Z. A Wrinkled PEDOT:PSS Film Based Stretchable and Transparent Triboelectric Nanogenerator for Wearable Energy Harvesters and Active Motion Sensors. Adv. Funct. Mater. 2018, 28, 1803684. [CrossRef]

114. Bu, T. Stretchable Triboelectric-Photonic Smart Skin for Tactile and Gesture Sensing. Adv. Mater. 2018, 30, 1800066. [CrossRef]

115. Yang, Z.W. Tribotronic Transistor Array as an Active Tactile Sensing System. ACS Nano 2016, 10, 10912-10920. [CrossRef] [PubMed] 
116. Wang, X. A Highly Stretchable Transparent Self-Powered Triboelectric Tactile Sensor with Metallized Nanofibers for Wearable Electronics. Adv. Mater. 2018, 30, 1706738. [CrossRef] [PubMed]

117. Chun, S. Self-Powered Pressure- and Vibration-Sensitive Tactile Sensors for Learning Technique-Based Neural Finger Skin. Nano Lett. 2019, 19, 3305-3312. [CrossRef]

118. Jiang, X.-Z. Integrated Flexible, Waterproof, Transparent, and Self-Powered Tactile Sensing Panel. ACS Nano 2016, 10, 7696-7704. [CrossRef] [PubMed]

119. Zhu, G. Self-Powered, Ultrasensitive, Flexible Tactile Sensors Based on Contact Electrification. Nano Lett. 2014, 14, 3208-3213. [CrossRef]

120. $\mathrm{Pu}, \mathrm{X}$. Ultrastretchable, transparent triboelectric nanogenerator as electronic skin for biomechanical energy harvesting and tactile sensing. Sci. Adv. 2017, 3, e1700015. [CrossRef] [PubMed]

121. Xiong, J. Skin-touch-actuated textile-based triboelectric nanogenerator with black phosphorus for durable biomechanical energy harvesting. Nat. Commun. 2018, 9, 4280. [CrossRef] [PubMed]

122. Chen, J. Self-Powered Triboelectric Micro Liquid/Gas Flow Sensor for Microfluidics. ACS Nano 2016, 10, 8104-8112. [CrossRef]

123. Ramuz, M. Transparent, Optical, Pressure-Sensitive Artificial Skin for Large-Area Stretchable Electronics. Adv. Mater. 2012, 24, 3223-3227. [CrossRef]

124. Yun, S. Polymer-Waveguide-Based Flexible Tactile Sensor Array for Dynamic Response. Adv. Mater. 2014, 26, 4474-4480. [CrossRef]

125. Wang, X. Piezophotonic effect based on mechanoluminescent materials for advanced flexible optoelectronic applications. Nano Energy 2019, 55, 389-400. [CrossRef]

126. Stoppa, M.; Chiolerio, A. Wearable Electronics and Smart Textiles: A Critical Review. Sensors 2014, 14, 11957-11992. [CrossRef]

127. Khan, H. Highly Sensitive Mechano-Optical Strain Sensor Based on 2D Material for Human Quality Gaits Monitoring and High-End Robotic Applications. J. Mater. Chem. C 2021, accepted.

128. Zou, L. Novel Tactile Sensor Technology and Smart Tactile Sensing Systems: A Review. Sensors 2017, 17, 2653. [CrossRef] [PubMed]

129. Gu, J. Wearable Strain Sensors Using Light Transmittance Change of Carbon Nanotube-Embedded Elastomers with Microcracks. ACS Appl. Mater. Interfaces 2020, 12, 10908-10917. [CrossRef]

130. Yi, H. Ultra-Adaptable and Wearable Photonic Skin Based on a Shape-Memory, Responsive Cellulose Derivative. Adv. Funct. Mater. 2019, 29, 1902720. [CrossRef]

131. Wang, X. Dynamic Pressure Mapping of Personalized Handwriting by a Flexible Sensor Matrix Based on the Mechanoluminescence Process. Adv. Mater. 2015, 27, 2324-2331. [CrossRef]

132. Boland, J.J. Within touch of artificial skin. Nat. Mater. 2010, 9, 790-792. [CrossRef] [PubMed]

133. Viriri, S.; Tapamo, J.R. Integrating Iris and Signature Traits for Personal Authentication Using User-SpecificWeighting. Sensors 2012, 12, 4324-4338. [CrossRef]

134. Jeong, S.M. Battery-Free, Human-Motion-Powered Light-Emitting Fabric: Mechanoluminescent Textile. Avd. Sustain. 2017, 1, 1700126. [CrossRef]

135. Wang, X. Automated Online Solid-Phase Derivatization for Sensitive Quantification of Endogenous S-Nitrosoglutathione and Rapid Capture of Other Low-Molecular-Mass S-Nitrosothiols. Anal. Chem. 2018, 90, 1967-1975. [CrossRef]

136. Wang, X. Full Dynamic-Range Pressure Sensor Matrix Based on Optical and Electrical Dual-Mode Sensing. Adv. Mater. 2017, 29, 1605817. [CrossRef] [PubMed]

137. Zhang, J.-C. Color Manipulation of Intense Multiluminescence from CaZnOS: $\mathrm{Mn}^{2+}$ by $\mathrm{Mn}^{2+}$ Concentration Effect. Chem. Mater 2015, 27, 7481-7489. [CrossRef]

138. Li, L. CaZnOS:Nd3+ Emits Tissue-Penetrating near-Infrared Light upon Force Loading. ACS Appl. Mater. Interfaces 2018, 10, 14509-14516. [CrossRef]

139. Zhang, J.-C. Creating Recoverable Mechanoluminescence in Piezoelectric Calcium Niobates through $\mathrm{Pr}^{3+}$ Doping. Chem. Mater. 2016, 28, 4052-4057. [CrossRef]

140. Larson, C. Highly stretchable electroluminescent skin for optical signaling and tactile sensing. Science 2016, 351, 1071-1074. [CrossRef]

141. Zhang, Z. Textile Display for Electronic and Brain-Interfaced Communications. Adv. Mater. 2018, 30, 1800323. [CrossRef] [PubMed]

142. Jeong, S.M. Simultaneous dual-channel blue/green emission from electro-mechanically powered elastomeric zinc sulphide composite. Nano Energy 2016, 21, 154-161. [CrossRef]

143. Yu, J. Highly skin-conformal wearable tactile sensor based on piezoelectric-enhanced triboelectric nanogenerator. Nano Energy 2019, 64, 103923. [CrossRef]

144. Li, T. From Dual-Mode Triboelectric Nanogenerator to Smart Tactile Sensor: A Multiplexing Design. ACS Nano 2017, 11, 3950-3956. [CrossRef]

145. Wang, X. Self-Powered High-Resolution and Pressure-Sensitive Triboelectric Sensor Matrix for Real-Time Tactile Mapping. Adv. Mater. 2016, 28, 2896-2903. [CrossRef]

146. Jin, L. Self-powered Real-time Movement Monitoring Sensor Using Triboelectric Nanogenerator Technology. Sci. Rep. 2017, 7, 10521. [CrossRef] [PubMed] 
147. Shin, Y.E. Sewing machine stitching of polyvinylidene fluoride fibers: Programmable textile patterns for wearable triboelectric sensors. J. Mater. Chem. A 2018, 6, 22879-22888. [CrossRef]

148. Rein, M. Diode fibres for fabric-based optical communications. Nature 2018, 560, 214-218. [CrossRef]

149. Yang, Y. Liquid-Metal-Based Super-Stretchable and Structure-Designable Triboelectric Nanogenerator for Wearable Electronics. ACS Nano 2018, 12, 2027-2034. [CrossRef]

150. Cai, Y. Extraordinarily Stretchable All-Carbon Collaborative Nanoarchitectures for Epidermal Sensors. Adv. Mater. 2017, 29, 1606411. [CrossRef]

151. Park, J. Fingertip skin-inspired microstructured ferroelectric skins discriminate static/dynamic pressure and temperature stimuli. Sci. Adv. 2015, 1, e1500661. [CrossRef]

152. Jang, K.-I. Rugged and breathable forms of stretchable electronics with adherent composite substrates for transcutaneous monitoring. Nat. Commun. 2014, 5, 4779. [CrossRef]

153. Kim, S.-W. A Triple-Mode Flexible E-Skin Sensor Interface for Multi-Purpose Wearable Applications. Sensors 2018, 18, 78. [CrossRef]

154. Zhou, K. Template-Directed Growth of Hierarchical MOF Hybrid Arrays for Tactile Sensor. Adv. Funct. Mater. 2020, $30,2001296$. [CrossRef]

155. Chen, J. Personalized Keystroke Dynamics for Self-Powered Human-Machine Interfacing. ACS Nano 2015, 9, 105-116. [CrossRef]

156. Chun, K.-Y. A Self-Powered Sensor Mimicking Slow- and Fast-Adapting Cutaneous Mechanoreceptors. Adv. Mater. 2018, 30, 1706299. [CrossRef] [PubMed]

157. Wang, Y. A highly flexible tactile sensor with an interlocked truncated sawtooth structure based on stretchable graphene/silver/silicone rubber composites. J. Mater. Chem. C 2019, 7, 8669-8679. [CrossRef]

158. Tuthill, J.C.; Wilson, R.I. Mechanosensation and Adaptive Motor Control in Insects. Curr. Biol. 2016, 26, R1022-R1038. [CrossRef] [PubMed]

159. Yin, B. Bioinspired and bristled microparticles for ultrasensitive pressure and strain sensors. Nat. Commun. $2018,9,5161$. [CrossRef]

160. Dechant, H.E. Arthropod touch reception: Stimulus transformation and finite element model of spider tactile hairs. J. Comp. Physiol. A. 2001, 187, 313-322. [PubMed]

161. Barth, F.G. Spider mechanoreceptors. Curr. Opin. Neurobiol. 2004, 14, 415-422. [CrossRef]

162. Li, T. Flexible Capacitive Tactile Sensor Based on Micropatterned Dielectric Layer. Small 2016, 12, 5042-5048. [CrossRef] [PubMed]

163. Reeder, J.T. 3D, Reconfigurable, Multimodal Electronic Whiskers via Directed Air Assembly. Adv. Mater. 2018, $30,1706733$. [CrossRef] [PubMed]

164. Kim, K. Tactile Avatar: Tactile Sensing System Mimicking Human Tactile Cognition. Adv. Sci. 2021, 8, 2002362. [CrossRef] [PubMed] 